Portland State University

PDXScholar

Summer 1-1-2012

\title{
Risk Factors for Homelessness Among Community Mental Health Patients with Severe Mental Illness
}

Rupert Talmage van Wormer

Portland State University

Follow this and additional works at: https://pdxscholar.library.pdx.edu/open_access_etds

Part of the Community Health Commons, Health Services Research Commons, and the Psychiatric and Mental Health Commons

Let us know how access to this document benefits you.

\section{Recommended Citation}

van Wormer, Rupert Talmage, "Risk Factors for Homelessness Among Community Mental Health Patients with Severe Mental Illness" (2012). Dissertations and Theses. Paper 653.

https://doi.org/10.15760/etd.653

This Dissertation is brought to you for free and open access. It has been accepted for inclusion in Dissertations and Theses by an authorized administrator of PDXScholar. Please contact us if we can make this document more accessible: pdxscholar@pdx.edu. 
Risk Factors for Homelessness Among Community Mental Health Patients with Severe Mental Illness

by

Rupert Talmage van Wormer

A dissertation submitted in partial fulfillment of the requirements for the degree of

Doctor of Philosophy

in

Social Work and Social Research

Dissertation Committee:

Kevin Corcoran, Chair

Daniel Coleman

Alma Trinidad

Karen Seccombe

Portland State University

2012 


\begin{abstract}
The purpose of this study was to identify risk factors associated with homelessness, assess the relationship between housing status and consumption of costly publicly funded resources, to identify characteristics associated with service retention, and to evaluate whether length of treatment is associated with better outcomes. The target population was homeless and formerly homeless adults with SMI enrolled in community mental health services at the Downtown Emergency Service Center SAGE mental health program located in Seattle. The sample consisted of 380 SAGE patients who had continuous enrollment in 2005 . These patients formed the cohort for the study. Agency records for these patients were reviewed for a 3-year period (2005-2007). The study utilized a non-experimental retrospective cohort study design. Multiple logistic regression, hierarchical multiple regression, two-way repeated measures ANOVA, and Cochran's Q test were used to analyze the data. Homelessness was associated with African American race, substance use, lower income, and younger age. Patients who were homeless spent more time in jail and required more mental health staff time compared with patients with stable housing. Patients with schizophrenia were more likely to retain services and African American patients were less likely to retain services. Overall, patients who remained enrolled in services from Year 1 to Year 3 had improved housing stability, fewer days of incarceration, and required less staff support. The overrepresentation of African Americans among patients who experienced homelessness suggests that racism could be a factor contributing to homelessness for this racial group. Further research is needed to assess the relationship between race and homelessness.
\end{abstract}




\section{TABLE OF CONTENTS}

\section{Page}

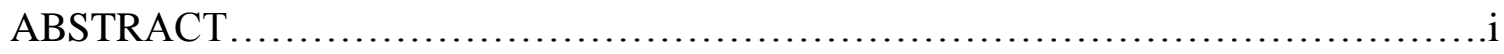

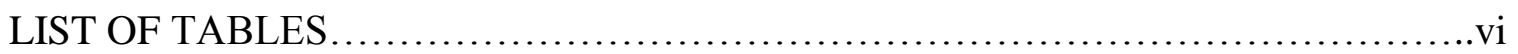

Chapter

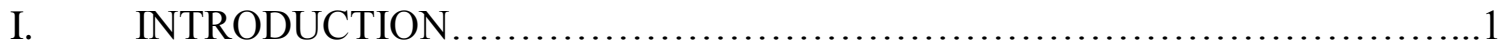

Background of the Study ..............................................

Social Problem Statement............................................... 2

Purpose of the Study...............................................

Motivation for the Study..............................................4

Relevance to the Social Work Profession.................................4

Significance of the Study............................................5

Operational Definitions...............................................

Theoretical Framework..................................................... 8

Research Questions................................................... 16

Hypotheses....................................................17

Organization of the Study............................................ 18

II. REVIEW OF THE LITERATURE.....................................19

Introduction..................................................... 19

Review of the General Literature on Homelessness...........................19

Magnitude of the Problem and Characteristics of the Population.........19

Risk Factors for Homelessness...............................21

The Consequences of Homelessness.............................24

Historical and Political Context....................................26 
Review of the Relevant Treatment Literature..............................36

Effective Interventions: Does Anything Work?....................................36

Cost-Effectiveness Analysis....................................40

Service Retention and Length of Treatment........................42

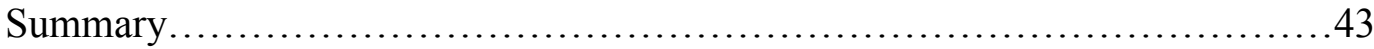

III. METHODOLOGY ................................................... 44

Introduction.......................................................... 44

Research Design....................................................44

Participants and Setting............................................... 45

Study Variables...................................................47

Data Collection...................................................49

Protection of Human Subjects..........................................50

Data Analysis.....................................................51

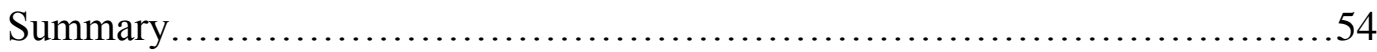

IV. PRESENTATION AND ANALYSIS OF DATA...........................55

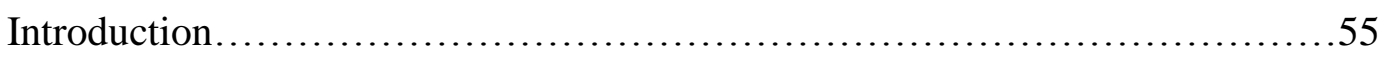

Descriptive Statistics...............................................55

Testing the Research Questions and Hypotheses............................61

Research Question One..........................................61

Hypothesis One................................................65

Research Question Two........................................65

Hypothesis Two...........................................67

Research Question Three..........................................68

Hypothesis Three...............................................73 
Research Question Four........................................73

Hypothesis Four............................................. 78

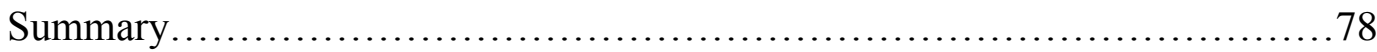

V. SUMMARY, DISCUSSION, AND CONCLUSIONS ........................80

Introduction............................................................ 80

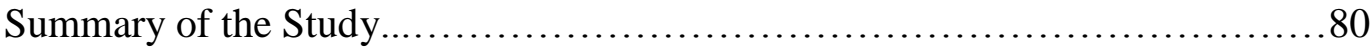

Discussion of the Findings............................................ 83

Research Question One and Hypothesis One.......................83

Race and homelessness....................................84

Substance use and homelessness.........................86

Income and homelessness..............................87

Age and homelessness.................................... 88

Gender and homelessness.................................89

Mental health disorders, GAF, and homelessness...............90

Research Question Two and Hypothesis Two.........................91

Incarceration and homelessness..........................91

Community mental health service hours and homelessness.......93

Utilization of inpatient psychiatric services and homelessness....96

Research Question Three and Hypothesis Three........................97

Mental health disorders, GAF, and service retention............97

Race and service retention................................ 99

Housing status and service retention...................... 100

Income and service retention............................. 100

Gender and service retention............................101 
Age and service retention..............................101

Substance use and service retention..........................102

Months of enrollment and service retention...................103

Research Question Four and Hypothesis Four......................103

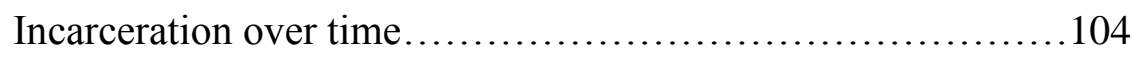

Outpatient mental health service use over time................105

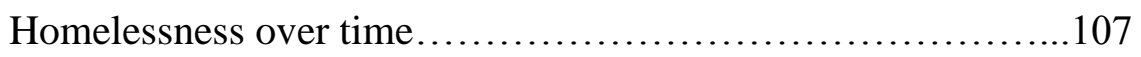

Psychiatric hospitalization over time......................108

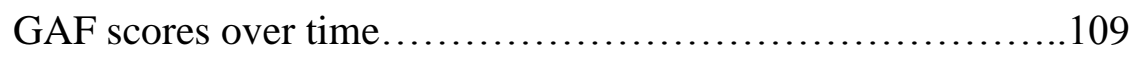

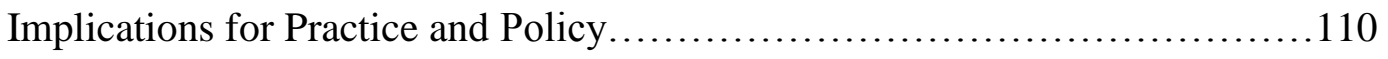

Recommendations for Further Research...............................114

Limitations ............................................................. 116

Conclusions......................................................118

REFERENCES............................................................ 121 


\section{LIST OF TABLES}

Table

Page

1. Descriptive statistics for age, income amount, and GAF.....................56

2. Descriptive statistics gender and race................................57

3. Descriptive statistics for income source.................................58

4. Descriptive statistics for housing status................................58

5. Descriptive statistics for mental health disorders..........................59

6. Descriptive statistics for substance use disorders.........................60

7. Descriptive statistics for incarceration, psychiatric hospitalization, and SAGE service hours....................................................... 61

8. Logistic regression predicting likelihood of homeless episodes...............64

9. Hierarchical multiple regression analyses predicting community resource utilization from housing status......................................67

10. Logistic regression predicting likelihood of patients retaining SAGE services...70

11. Chi-square tests to evaluate whether characteristics of patients who retained services differed from patients who did not retain services.....................72

12. Independent samples t-tests to evaluate whether characteristics of patients who retained services differed from patients who did not retain services...............73

13. Descriptive statistics for number of days in jail by service year and African American race, substance use disorder, and one or more episodes of homelessness.

14. Descriptive statistics for number of days of psychiatric hospitalization by service year and African American race, substance use disorder, and one or more episodes of homelessness........................................... 75

15. Descriptive statistics for number of SAGE service hours by service year and African American race, substance use disorder, and one or more episodes of homelessness........................................................76 
16. Descriptive statistics for GAF scores by service year and African American race, substance use disorder, and one or more episodes of homelessness..............76

17. Cochran's Q test to evaluate whether the proportion of SAGE patients experiencing homelessness changed over a 3-year period of continuous enrollment in the SAGE program.....................................77 


\section{CHAPTER I}

\section{INTRODUCTION}

\section{Background of the Study}

Many studies have been conducted on the topic of homelessness beginning with the "Skid Row studies" of the 1950s and 1960s (Rossi, 1989). These early studies, including those conducted by Bogue (1963) and Bahr (1969) mostly sought to identify characteristics of the people inhabiting Skid Row areas of major cities, referring to these people as homeless though many of these individuals paid rent and lived in small rooms or cubicles in "flophouses" and would not be considered homeless by today's standards (Rossi, 1989, pp.29-30). More recently, researchers have been turning their attention towards evaluating the effectiveness of specific homeless interventions and evaluating the cost benefits of programs that provide housing to homeless individuals.

However, despite the progress that has been made, there continues to be a need for additional research on homelessness. Specifically, there is a need for research that examines specific subsets of the homeless population in greater detail and that identify interventions that are effective in reducing homelessness for individuals belonging to these different subsets (Nelson, Aubry, \& Lafrance, 2007).

This study differs from past studies on homelessness in several important ways. One distention is its focus on a specific subset of the homeless population that has not received sufficient previous research attention: homeless adults with severe mental illness (SMI). Another difference is the study used existing data from a community mental 
health program that is unique in that it specializes in providing ongoing services to homeless and formerly homeless single adults. This guaranteed a reasonably large sample size of participants who were of the population of interest for the study.

Furthermore, the patients served by this program were formally assessed by licensed mental health staff, including psychiatrists and other mental health professionals, therefore the clinical data used for this study was likely more diagnostically accurate than past studies that have relied on data based on self-report or clinical assessments by nonprofessionals.

The community mental health program where the data was collected is located in Seattle, Washington and is referred to by the acronym SAGE, which stands for Support, Advocacy, Growth, and Enhancement. The purpose of this research was to identify risk factors associated with homelessness within this patient population, to assess the relationship between housing status and consumption of costly publicly funded resources, to identify characteristics associated with service retention, and to evaluate whether length of treatment for these individuals is associated with better patient outcomes.

\section{Social Problem Statement}

Homelessness among persons with SMI is a major social problem in the United States. Homelessness for this subset of the homeless population results in high costs for both the individuals experiencing homelessness as well as for society as a whole. For the individuals who are homeless the costs are primarily the psychological and physical harm directly associated with the increased vulnerability of life on the streets and in public 
shelters. The day-to-day experience of these individuals sharply contrasts that of the security, comfort, and stability of life for individuals with permanent housing (Power et al., 1999; Davis, 2004).

The cost for the society, on the other hand, of having large numbers of persons with SMI living in the community without housing is both financial and social. The financial costs include public expenses associated with the unnecessary, excessive, or inappropriate use of costly publicly funded services such as psychiatric hospitalizations and involvement in the criminal justice system by individuals who would have been better served elsewhere in the system. The social costs include a diminished quality of life for everyone in the society due to the negative impact on communities that results from persons with SMI living in public places (e.g. exposure to aggressive panhandling, theft, intoxication, bizarre and aggressive behavior and people with unsanitary hygiene and untreated communicable diseases when non-homeless individuals utilize public parks, libraries, restrooms, and transportation).

\section{Purpose of the Study}

The purpose of the study was to identify risk factors associated with homelessness within this patient population, to assess the relationship between housing status and consumption of costly publicly funded resources, to identify characteristics associated with service retention, and to evaluate whether length of treatment for these individuals is associated with better patient outcomes. 


\section{Motivation for the Study}

My motivation for conducting this study was driven by my personal and professional goal of making a meaningful contribution to the effort to end or at a minimum reduce homelessness among individuals with SMI. The aim of this study is consistent with this goal. For example, identifying risk factors for homelessness could lead to the creation of interventions designed to better assist individuals most at risk and in turn hopefully result in decreased homelessness among these individuals. Assessing the relationship between homelessness and utilization of costly publicly funded services could provide evidence of the cost-benefits of reducing homelessness, which could lead to increased spending on interventions that could further reduce homelessness for individuals with SMI.

\section{Relevance to the Social Work Profession}

This study is relevant to the social work profession in that it focuses on issues related to social welfare and social justice, both major concerns of social work. Section 6.01 of the NASW Code of Ethics states: "Social workers should advocate for living conditions conducive to the fulfillment of basic human needs and should promote social, economic, political, and cultural values and institutions that are compatible with the realization of social justice" (NASW, 2008). This study, with its aim of acquiring knowledge related to homelessness among persons with SMI for the purpose of contributing to the amelioration of this social problem, is consistent with these core social work values. It is also consistent with social work policy, as stated in Social Work 
Speaks (NASW, 2006), that social workers should advocate for the development of a continuum of care and supportive services for the prevention of homelessness.

\section{Significance of the Study}

A major significance of this study is that it focused on a specific subgroup of the homeless population in greater detail than most previous studies and with more certainty that the sample population is in fact members of this subgroup. Because of this, the results should be useful to policymakers and program administrators who are working on finding ways to improve services for this especially vulnerable subset of the homeless population.

Another significance of the study is that it examined the social problem of homelessness from the perspective of a community mental health program that has been serving homeless and formerly homeless patients since 1997. This mental health program is unique both in terms of its clientele-homeless and formerly homeless men and women — and in terms of its treatment philosophy — using a harm reduction model. Moreover, the fact that many of the patients receiving mental health treatment experienced homelessness while others experienced periods of stable housing made comparisons between these groups possible. Due to the uniqueness of this research setting and the fact that the population size is reasonability large, the findings should be of some significance. This research should help fill gaps in the literature on homeless persons who receive community-based mental health services for serious mental health disorders. Other recent studies on this topic have largely been from the perspective of 
emergency shelters, jails, psychiatric hospitals, newly started pilot projects, or from supportive housing projects. The unique perspective of this study could potentially result in new insights on this social problem and should have considerable policy as well as treatment implications.

The study is also expected to result in direct benefits for the agency that is participating in the study. The agency will receive a copy of the results which will be used for quality improvement purposes. The findings of the study will enhance the agency's understanding of the patients they serve. This could result in service improvements for the patient population through better training for staff and it could possibly lead to the creation of targeted interventions for at risk patients including patients at risk for homelessness or for dropping out of services.

A clear need exists for additional research on the topic of homelessness among persons with SMI. While many studies have been conducted on the topic of homelessness, few have focused specifically on homeless persons with SMI. Moreover, as Padgett, Gulcur, and Tsemberis (2006) suggest, the literature on homeless adults with SMI is generally silent on the details of programming for this population. If interventions are to be effective in assisting this subset of the homeless population, then more needs to be known about the background characteristics of this subset including demographic and clinical characteristics, risk factors associated with homelessness, and this subset's use of costly publicly funded services. There is also a need for more research that examines patient characteristics associated with service retention as well as the relationship 
between length of enrollment in community mental health services and better patient outcomes.

\section{Operational Definitions}

For the purposes of the study, the term homeless person is defined according to the federal definition of homelessness established in the Stewart B. McKinney Homeless Assistance Act of 1987, 42 U.S.C. $§ 11302$, et seq.:

An individual who lacks a fixed, regular, and adequate nighttime residence; and an individual who has a primary nighttime residence that is-- (A) a supervised publicly or privately operated shelter designed to provide temporary living accommodations (including welfare hotels, congregate shelters, and transitional housing for the mentally ill); (B) an institution that provides a temporary residence for individuals intended to be institutionalized; or (C) a public or private place not designed for, or ordinarily used as, a regular sleeping accommodation for human beings.

Severe mental illness (SMI) is defined as a diagnosis of a DSM-IV-TR Axis I mental health disorder that affects an individual's ability to function to the degree that he or she is eligible for state (Washington Department of Social and Health Services) or federal government (Social Security Administration) cash or medical benefits including General Assistance, Supplemental Security Income, Social Security Income, Medicaid, and/or Medicare. Co-occurring disorders is defined as a diagnosis of both a DSM-IV-TR Axis I mental health disorder as well as a DSM-IV-TR Axis I substance use disorder. 


\section{Theoretical Framework}

The public health model is the organizing theoretical framework of the dissertation. Health promotion and harm reduction are the major components of this model relevant to the dissertation. Public health is defined by Ball (2007) as the "collective efforts aimed at improving the health of populations, including the prevention of ill-health, the treatment, amelioration, control of disease and the promotion of wellbeing” (p. 685). Countries that had adopted a public health model to drug-related problems, such as The Netherlands and United Kingdom, were best equipped to respond rapidly when HIV emerged among intravenous drug users, according to Andrew Ball, a staff member of the World Health Organization (WHO). This is because they had already setup up harm reduction programs to reduce the spread of Hepatitis $\mathrm{C}$ among intravenous drug users. Health promotion is "any planned combination of educational, political, environmental, regulatory, or organizational mechanisms that supports actions and conditions of living conducive to the health of individuals, groups, and communities" (Joint Committee on Health Education and Health Promotion Terminology, 2001). The WHO's Ottawa Charter for Health Promotion (1986) describes health promotion as the process of enabling people to increase control over, and to improve, their health. This charter lists the following as prerequisites for health: peace, shelter, education, food, income, a stable eco-system, sustainable resources, social justice, and equity.

In 1973 the WHO called for the primacy of public health over the drug control approach as a means of reducing the harmful effects of substance abuse on communities (Ball, 2007). Later in that same year the $20^{\text {th }}$ WHO Expert Committee on Drug 
Dependence recommended harm reduction as a practical replacement for the drug control approach.

The public health model offers a framework for providing a spectrum of health and mental health services to homeless persons. The public health model, according to Conklin (2004), stresses: assessment, effective treatment, health education, prevention measures, and continuity of care. The basic values of this model are: wellness, treatment of disease, prevention of illness, and access to care. The provision of housing for homeless persons is consistent with "established public health mandates to control communicable diseases and promote effective prevention measures” (p. 121).

Also within the public health model framework, and essential to health promotion, is the concept of risk (World Health Organization, 2002). Risk has to do with the probability that a future event will occur based on one or more conditions currently present (Fraser \& Richman, 1999). These conditions are referred to as risk factors. Risk factors could be genetic, environmental, or behavioral. People described as "at risk" are people who have characteristics similar to others in the population who developed a particular problem (p.132). For example, an individual who has excessive sun exposure, does not use sunscreen, and has a family history of skin cancer, could be described as being at risk for developing skin cancer. Multiple risk factors, such as in this example, can have a cumulative effect of further increasing the likelihood that an individual will develop a given problem. 
Empirical evidence of the relationship between risk factors and specific problems has been used to design and select interventions aimed at reducing individuals' risk for developing these problems (Jenson, 2007). Interventions to reduce risk tend to focus on modifiable risk factors, such as smoking and exercise in relationship to heart disease. Research to identify risk factors began in the 1960s with the study of heart disease and later expanded to include social problems such as substance abuse and delinquency (p.3).

Harm reduction is an example of a public health intervention that was developed to reduce risks among persons belonging to groups considered to be at high risk and who are also socially marginalized and not easily reached by more traditional or mainstream approaches (Peterson, Dimeff, Tapert, Stern, \& Gorman, 1998). Harm reduction is a public health alternative to the moral, criminal, and other abstinence-only models of drug use and addiction (Marlatt, 1998). This definition does not exclude the disease model. Nor does it exclude abstinence from drinking and illicit drug use as a long-term goal. Ball (2007) defines the harm in harm reduction in terms of injury or damage that occurs at different levels — individual, family, community, society — and in different formshealth, economic, social. Harm reduction began as a pragmatic approach for reducing the negative consequences of drug addiction (e.g. heroin users contracting HIV from sharing contaminated syringes) and has since broadened its scope. The concept of harm reduction is also used more widely to pertain to broader public health issues such as adolescent gender and other risk-taking behaviors, domestic violence, and prostitution (Marlatt, 1996; Tsemberis et al., 2004). WHO, for example, is developing the harm reduction component of a broader public health model for HIV/AIDS prevention and care 
(Ball, 2007). Harm reduction provides a pragmatic and compassionate approach to address the problems of the need for treatment and housing for individuals who are chronically homeless (Tsemberis \& O’Callaghan, 2004).

Harm reduction operates at both the policy and practice levels. At both levels, the first priority is to minimize the negative consequences and damage to both individuals and society associated with substance use, mental illness, and homelessness. In working with clients, at the practice level, practitioners "meet the client where the client is" to help him or her become motivated for change. In contrast to zero-tolerance or abstinence-only models of addiction, housing programs that embrace a harm reduction provide housing as a basic right. From this perspective, housing and treatment are seen as separate domains: Clients are housed because they are homeless (Tsemberis, \& O'Callagham, 2004). Access to housing is not dependent on being alcohol free or drug free. The provision of clean and safe housing is designed to fulfill all the basic goals of the public health model - to improve overall health and wellness, provide treatment of disease, prevent further illness, and provide continuity of care.

Harm reduction as related to homelessness is an alternative to the more mainstream moral and abstinence-only models. The moral model views drug use as morally wrong and with those using or possessing certain drugs deserving of punishment (Marlatt, 1998). Much of United States drug policy is influenced by this view. From this traditional perspective, total abstinence is the only acceptable treatment goal at the start of treatment. Harm reduction, on the other hand, regards abstinence as an ideal long-term goal, but accepts other treatment goals that focus on reducing harm to the individual and 
society such as decreasing the amount of substances a person uses to improve his or her health or decreasing needle sharing among intravenous drug users to reduce the spread of HIV within a community. When lack of housing is an issue, the traditional approach provides treatment first, and housing only afterwards; the harm reduction approach, in contrast, provides housing first.

The harm reduction model is defined in the Social Work Dictionary as: "a pragmatic, public health approach to reducing the negative consequences of some harmful behaviors rather than eliminating or curing them" (Barker, 2003, pp. 190-191). Alan Marlatt (1996), advocates for pragmatic policies geared to saving lives such as needle exchanges, methadone maintenance, education for safer sexual and drug use practices, and opportunities to engage in non-confrontational, client-centered counseling. The concept of harm reduction is especially relevant to work with clients who have severe psychotic disorders and who have difficulty with medication compliance, such as either not taking medications consistently or refusing medications altogether (Tsemberis \& O’Callaghan, 2004). Clinicians practicing harm reduction are able to assist clients who are reluctant to accept more traditional mental health services by offering services clients might be more willing to accept, including assistance with obtaining basic necessities (e.g. food, clothing, and shelter). Engaging clients in this way helps establish rapport. The thinking is that once trust is established the client may be more motivated to consider more traditional treatment options including medication and/or psychotherapy. The fundamental principle that applies here is what Patt Denning (2000) terms low threshold access: 
Services are offered with the least amount of requirements or restrictions, so that as many people as possible can take advantage of and benefit from them. Such a philosophy attempts to include many people in treatment in order to reduce harm not only to the individual but also to his or her family and community. The patient has few "hoops" to jump through, often not having to agree to come at a certain time or being asked for identification. Patients are not denied one service because they refused another that was linked to it. (p. 32)

The focus is always on reducing the harm and on enhancing the client's motivation toward adapting a healthier lifestyle. The practice or treatment side of harm reduction is a client-centered approach known as motivational interviewing.

Because a high proportion of homeless or formerly homeless persons with SMI have serious problems with drinking and illicit drugs as well, programs that coordinate pharmacotherapy, psychosocial treatments, and substance abuse counseling into a single comprehensive package are most likely to have good treatment outcomes (Green et al., 2007; Mueser et al., 2003). Integrated treatment programs for patients with substance use problems in addition to mental illness should include interventions tailored to the patient's motivation for change (e.g., the use of motivational interviewing techniques to develop motivation to address substance use); comprehensive services (e.g., medication management, rehabilitation, and social support interventions); and a long-term perspective, since relapse is a common occurrence (Green et al., 2007). 
Consistent with the principles of harm reduction, the overarching goal of motivational interviewing is to reinforce the client's wishes to protect himself or herself from harm (Miller \& Rollnick, 2002). Choice is a major theme here; for the homeless person with SMI, the choice may be whether or not to move into supportive housing. Motivational treatment is built on principles of psychology geared to enhance an individual's motivation to change.

A major influence for the development of motivational interviewing was the transtheoretical model (TTM) of intentional human behavior change, often referred to as the readiness to change model (Prochaska, DiClemente, \& Norcross, 1992). A key component of TTM is the stages of change, comprised of the following five stages: precontemplation, contemplation, preparation, action, and maintenance. From a public health perspective, clients need different health education strategies to promote consistency in practicing newly acquired behavior change and prevent a return of highrisk behaviors (Doyle \& Ward, 2001). Motivational interviewing along with TTM's stages of change, because of their demonstrated effectiveness, are the favored modality of clinicians practicing harm reduction (Marlatt, 1998).

The establishment of harm reduction programs in the United States has not been easy as they frequently face stiff public and political resistance. For example, the Downtown Emergency Service Center's 1811 Eastlake Project, a non-abstinence-based housing project for alcohol dependent homeless adults that allows its residents to drink in their rooms, was delayed for two years by a lawsuit initiated by neighboring businesses to stop it from being constructed (Murakami, 2005). The case went all the way to the 
Washington State Supreme Court before construction was allowed to begin (East Downtown Community Association v. Downtown Emergency Service Center, 2003). The project has also received much criticism from conservative local radio talk show hosts including John Carlson who referred to it as, "bunks for drunks... a living monument to failed social policy... aiding and abetting someone's self-destruction” (Kowal, 2006).

Consistent with the basic principles of health promotion and harm reduction, the study sought to identify relationships between key variables that could contribute to pragmatic solutions to promote health and reduce harm to individuals and society. The public health models of health promotion and harm reduction were chosen as the guiding framework for this dissertation for a number of reasons:

(1) The provision of housing to otherwise homeless people can be considered health promotion and harm reduction as housing provides protection from the elements, disease, poor nutrition, and violent victimization.

(2) Health promotion and harm reduction define the measurements themselves. Several of the key relationships to be studied are essentially measurements of an increase or reduction in harm. For example, the harms that are key variables in this study are the number of psychiatric hospitalizations by housed formerly homeless and currently homeless persons, and the number of incarcerations by these two groups of people in a one year period. Psychiatric hospitalizations and incarcerations can be considered harms because they generally occur when patients are less stable and therefore can be viewed as 
indicators of patient instability and they are also harms to society in terms of public cost.

(3) Health promotion and harm reduction at the practice level enter into this study in terms of the study measuring the impact of long-term treatment services on preventing homelessness, hospitalizations, and incarcerations.

(4) The recommendations that will emerge from these findings will relate to how public health problems can be ameliorated with improvements in the services rendered. For example, increased knowledge of risk factors related to homelessness among persons with SMI could lead to improved homelessness prevention programs for persons with SMI.

(5) Health promotion and harm reduction are consistent with the empowerment and strengths perspectives that guide social work policy and practices. Health promotion and harm reduction practices like the strengths perspective are built on the belief that "we best service clients by collaborating with them" (Saleebey, 2006) and that by emphasizing people's strengths we can help them draw on their own resources.

\section{Research Questions}

The study included four research questions. The first research question asked: Among community mental health patients, which patient characteristics (i.e. age, gender, race, income, DSM-IV-TR Axis I disorder[s], and DSM-IV-TR GAF score) are associated with episodes of homelessness when comparing patients who experienced homelessness with those who did not? 
Running head: RISK FACTORS FOR HOMELESSNESS AMONG MENTAL HEALTH PATIENTS

The second question asked: Do homeless community mental health patients consume more community resources (i.e. jail, psychiatric hospitalizations, and SAGE service hours) than patients with housing?

The third research question asked: Among community mental health patients, which patient characteristics (i.e. housing status, age, gender, race, income, DSM-IV-TR Axis I disorders(s) and DSM-IV-TR GAF score) are associated with service retention?

Lastly, is length of enrollment in community mental health services associated with patient outcomes for the following: days in jail, days in psychiatric hospital, SAGE service hours, DSM-IV-TR GAF scores, and housing status?

\section{Hypotheses}

The study tested the following hypotheses:

- There is an association between patient characteristics (i.e. age, gender, race, income DSM-IV-TR Axis I disorder[s], and DSM-IV-TR GAF score) and housing status.

- There is an association between patient housing status and patient utilization of community resources (i.e. jail, psychiatric hospitalizations, and SAGE service hours).

- There is an association between patient characteristics (i.e. housing status, age, gender, race, income, DSM-IV-TR Axis I disorders[s] and DSM-IV-TR GAF score) and service retention. 
Running head: RISK FACTORS FOR HOMELESSNESS AMONG MENTAL HEALTH PATIENTS

- Patient outcomes (i.e. days in jail, days in psychiatric hospital, SAGE service hours, DSM-IV-TR GAF scores, and housing status) differ based on how long a patient has been enrolled in services.

\section{Organization of the Study}

This research study is presented in five chapters. Chapter One includes the background of the study, social problem statement, purpose of the study, motivation for the study, relevance to the social work profession, significance of the study, operational definitions, theoretical framework, research questions, and hypotheses.

Chapter Two presents a review of the literature, which includes magnitude of the problem, characteristics of the population, risk factors for homelessness, consequences of homelessness, historical and political context, effective interventions, cost-effectiveness analysis, service retention, and effect of length of treatment on outcomes. Chapter Three describes the methodology used for this research study. It includes a description of the research design, participants and setting, study variables, data collection, protection of human subjects, and data analysis procedures.

Chapter Four presents the study's findings including descriptive statistics, testing of the research questions and hypotheses, and results of the analyses for the four research questions and hypotheses. Chapter Five provides a summary of the study, discussion of the findings, implications for practice and policy, recommendations for further research, limitations, and conclusions. 


\section{CHAPTER II}

\section{REVIEW OF THE LITERATURE}

\section{Introduction}

A review of the literature related to this study and the social problem of homelessness among persons with SMI is presented in this chapter. This review is divided into two main sections. The first section is a review of the general literature on homelessness. The second section is a review of the relevant treatment literature.

\section{Review of the General Literature on Homelessness}

Presented in the first section of this chapter is a review of the general literature on homelessness. This review examines the magnitude of the problem of homelessness, characteristics of the homeless population, risk factors for homelessness, and consequences of homelessness. This is then followed by a discussion of the historical and political context related to this social problem.

\section{Magnitude of the Problem and Characteristics of the Population}

Over the past few decades, homeless persons with mental illness have become an increasingly visible part of many urban communities. It is difficult to know the exact number of these individuals as homeless people in general are a difficult population to count due to their lack of fixed addresses. Trying to ascertain how many homeless individuals have a mental illness is even more challenging as this would likely require 
psychiatric assessments or assess to psychiatric treatment records to verify mental health status. This means only rough estimates are available.

The most recent national estimates come from the U.S. Department of Housing and Urban Development (HUD) in their 2010 Annual Homeless Assessment Report to Congress (HUD, 2010). This report includes an annual estimate and a one-night count, point-in-time estimate. According to this report, 1,593,150 unduplicated individuals (single adults, couples, families with children, and youth) stayed in emergency shelters and transitional housing during a one-year period from October 1, 2009 to September 30, 2010 (p.11). Of these individuals, 1,027,788 (65\%) were adults unaccompanied by children. Among the sheltered homeless individuals, $71 \%$ were male, $47 \%$ were White, non-Hispanic, 35\% African American, 9\% White Hispanic, 4\% other single race, and 6\% were reported as other or multiracial (p.20). This estimate is based on Homeless Management Information System data submitted to HUD from homeless service providers receiving HUD funding and others participating voluntarily. These data do not include homeless individuals who did not utilize shelters during this one-year period. Much less is known about homeless individuals who do not stay in shelters.

According to this same HUD report, on a single night in January 2010 there were an estimated 649,917 sheltered and unsheltered homelessness individuals living in communities throughout the United States (p. 5). This figure is based on a tabulation of communitywide one-night counts conducted by volunteers and homeless service providers throughout the United States. Of the individuals counted in the one-night counts, 403,543 (62\%) were staying in shelters or transitional housing and 246,374 (38\%) 
were observed sleeping in public places by one-night count volunteers (p.6). Homeless service providers reported that $26 \%$ of the adults staying in shelters and transitional housing were individuals with SMI (p.18). This compares with an estimated $6 \%$ of the general adult population (Kessler, Chiu, Demler, \& Walters, 2005).

While HUD's report on homelessness likely underestimates the total numbers of individuals experiencing homelessness, it does provide evidence that a large number of individuals are homeless including a significant number of persons with SMI.

\section{Risk Factors for Homelessness}

While it is clear that not all individuals who are mentally ill become homeless, it is likely that certain factors, including mental illness, increase the likelihood an individual will become homeless. A study by Folsom et al. (2005) on prevalence and risk factors for homelessness among persons with SMI found that 1,551 (15\%) of 10,340 individuals treated for schizophrenia, bipolar disorder, or major depression in the public mental health system in San Diego County, California, were homelessness. At the time of this study, the population of San Diego County was approximately 2,900,000 with an estimated $15,000(0.5 \%)$ of these individuals homeless at any giving time (p.371). These figures indicate that public mental health patients with SMI were 30 times more likely to be homeless than were members of the general population of San Diego County.

Using multivariate logistic regression analysis, Folsom et al. also compared homeless and non-homeless patients on the demographic and clinical characteristics. The following variables were included in the analysis: gender, ethnicity, substance use 
disorder, psychiatric diagnosis, and mean DSM-IV-TR Global Assessment of Functioning score (GAF). The results indicate that male gender, African American ethnicity, substance use disorder, schizophrenia, bipolar disorder, and lower GAF scores were associated with higher rates of homelessness (p.373).

With this study, Folsom et al. helped to establish SMI as a risk factor for homelessness. This study also provides evidence of additional risk factors for homelessness among individuals with SMI including male gender. Males made up 62\% of the homeless individuals in this study (p.372). This finding is consistent with studies from the general homeless population that have also found the majority of homeless individuals are men (Burt et al., 1999; U.S. Census Bureau, 2001; HUD, 2010). As a result, many programs that provide services for homeless adults are geared toward men despite evidence that indicates that the needs of homeless men and women differ (SAMHSA, 2003b). A high proportion of homeless women with SMI have been victims of violence, either prior to or after becoming homeless, and "require trauma-sensitive services to help them regain psychiatric and residential stability" (p.15). However, these services are often not readily available.

Folsom et al. (2005) also identified African American ethnicity as a risk factor for homelessness. They found that while African Americans constituted 5\% of the local population, $15 \%$ of homeless adults served in the public mental health system in San Diego County were African American (p.374). Studies of the general homeless population from the 1980s (Rossi, 1989) to the most recent studies (U.S. Conference of Mayors, 2007; HUD, 2010) have consistently found that African Americans are over- 
represented within the general homeless population. African Americans are $13 \%$ of the U.S. population (U.S. Census Bureau, 2010) but are estimated to make up more than $30 \%$ of general homeless population (U.S. Conference of Mayors, 2007; HUD, 2010). The reason for this over-representation is not known and few studies have specifically addressed this issue (Hopper, 2003). However, it is likely that persons from disadvantage backgrounds who have historically faced discrimination in housing, education, and employment are at greater risk of becoming homeless (p.157).

Presence of a substance use disorder has also been identified as a risk factor for homelessness among persons with SMI (Folsom et al., 2005). Folsom et al. found that among homeless patients with SMI enrolled in the San Diego County Adult Mental Health Services, $61 \%$ were diagnosed with a substance use disorder compared with only $21 \%$ of the non-homeless mental health patients (p.372). Studies on the general homeless population have also indicated that a large proportion of homeless individuals have a substance use disorder (Burt, Aron, Lee, \& Valente, 2001; HUD, 2010). The literature suggests that nearly $50 \%$ of mental health patients with schizophrenia have a cooccurring substance use disorder (Green, Drake, Brunette, \& Noordsy, 2007). This is a rate about three times as high as that of the general population. Patients with cooccurring disorders are highly prone to experiencing negative outcomes in addition to homelessness. This includes increased symptom severity, increased rates of hospitalization, infectious illnesses, violence, victimization, and medical noncompliance (Mueser, 2003). 


\section{The Consequences of Homelessness}

The consequences of homelessness for persons with SMI can be devastating for the individuals experiencing homelessness and can also have a negative impact on the communities they live in. Homeless individuals suffer many problems directly related to their lack of housing. Cohen (2001) describes the living situation of homeless persons as, "highly precarious, fraught with daily uncertainties about meeting basic survival needs" (p. 635). Preexisting mental and physical health conditions tend to worsen due to the difficultly of receiving regular health care while homeless (National Coalition for the Homeless, 2009a). Mortality rates among homeless persons are 10 to 40 times greater than the general population of comparable age and gender (Rossi, 1989). Common health problems for this population include: malnutrition, diabetes, liver disease, neurological impairments, pulmonary and heart disease, upper respiratory infections, skin conditions, and serious dental health problems (SAMHSA, 2003b). Homeless people also have an increased risk of contracting infectious diseases such as tuberculosis, Hepatitis B and C, and HIV/AIDS (p.14). A study from Public Health—Seattle and King County using data from 2004 to 2007 found that the average life expectancy of homeless individuals in King County, Washington is only 48 years compared to approximately 80 for the U.S. (Public Health—Seattle and King County, 2009). Of the 374 homeless deaths that occurred over this 4 year period, 38\% died of natural causes, $29 \%$ died of acute intoxication, $14 \%$ from accidents, $7 \%$ from suicide, $7 \%$ from homicide, and for $4 \%$ the cause of death was not determined (p.5). 
Another consequence of homelessness for persons with SMI can be jail or prison. Many homeless individuals with SMI have been jailed or imprisoned for offences directly related to either their mental illness or lack of housing. Mentally ill homeless people have more frequent contact with the legal system and are more likely to end up in jail or prison than homeless people who do not suffer from mental illness (National Coalition for the Homeless, 2006). According to statistics released by the U.S. Department of Justice in $2005,13 \%$ of state prison inmates and $17 \%$ of jail inmates both were homeless prior to incarceration and met the DSM-IV-TR criteria for a mental health disorder (James \& Glaze, 2006). Details of the criminal offenses and severity of the mental illness were not provided. New laws that appear to be targeting homeless individuals may be contributing to this high rate of incarceration. For example, in Berkeley, California, the city council in 2007 unanimously voted to approve a new city ordinance that bans lying on sidewalks, public urination and defecation, possessing a shopping cart, and shouting in public (Jones, 2007). Policies, such as these, that are used to prosecute homeless persons, are referred by homeless advocates as "the criminalization of homelessness" (National Coalition for the Homeless, 2003).

Homelessness among persons with SMI has also resulted in high utilization of expensive emergency medical services. People in extreme poverty are sometimes left with no other choice but to exploit whatever resources are still available to them (Hopper, 2003). Hospital emergency departments (EDs) are open 24 hours a day and laws limit their ability to turn people away. A retrospective cohort study by O'Toole, Pollini, Gray, et al. (2007) found that among medically ill substance-using adults identified as high 
utilizers of ED services at two Baltimore hospitals, homelessness was a significant factor for predicting hospital utilization $(\mathrm{AOR}=2.07, \mathrm{p}<.05)$. High utilization was defined as three or more ED visits during a 12-month period. Of the 326 individuals who met the high utilizer definition, $21 \%$ reporting being homeless.

\section{Historical and Political Context}

Homelessness among persons with SMI in the United States, according to most accounts, is a social problem with a relatively short history, only dating back about 30 years. In the 1980 s, the homeless population, "shifted from a generally homogenous group of elderly, alcoholic males to a heterogeneous mix of individuals and families confronting poverty, substance use, and mental illness" (Coughey et al., 1999). Some authors use the words "new" and "old" homeless to describe these groups (Rossi, 1989). Prior to this homelessness was much less visible and was often confined to Skid Row neighborhoods (Hopper, 2003).

The emergence of this new social problem was shocking to many people who first witnessed it in the late 1970s and early 1980s. Describing this, Jencks writes: "Americans began noticing more people sleeping in public places, wandering the streets with their possessions in shopping bags, rooting through garbage bins in search of food or cans, and asking for handouts" (Jencks, 1994, p.v). By the 1990s, homelessness became, "a routine fixture on the local landscape" (Hopper, 2003, p.180). The sight of disheveled persons, some talking to themselves, making strange body movements, walking in traffic, 
or wearing winter coats in midsummer, was also becoming an increasingly ordinary occurrence in many urban American communities.

Many different historical factors contributed to the growth of homelessness among persons with SMI. Three factors of particular significance include the failure of community mental health centers to materialize in the wake of deinstitutionalization in the 1960s (Cohen, 2001), changes to involuntary commitments laws in the 1960s and 1970s (Rossi, 1989; Seager, 1998), and the diminishing availability of affordable housing in the 1970s and 1980s (Jencks, 1994; Davis, 2004; National Coalition for the Homeless, 2009b).

The relationship between deinstitutionalization and homelessness among persons with SMI is fairly complex. Widespread homelessness did not occur immediately following the release of thousands of mental health patients in the 1960s and early 1970s. Rather, as Cohen (2001) explains, "It was only when psychiatric disability interacted with the low-income housing shortage...that homelessness and mental illness became associated" (p.630). Furthermore, as Rossi (1989) points out, "Many of the chronically mentally ill homeless would have been admitted [to psychiatric hospitals] two decades ago under then-existing practices" (p.41).

In 1955, nearly half a million patients were involuntarily confined to state mental health institutions (Barusch, 2002). Influenced by a public that began to increasingly view state mental hospitals as cruel and dehumanizing, Congress passed the Mental Retardation Facilities and Community Mental Health Centers Construction Act in 1963 
(Kelley, 1998). This Act provided funding for the construction of community mental health centers (CMHC) throughout the country and was vocally supported by President John F. Kennedy (Sharfstein, 2000). At the time of its passage it was widely believed by many people that these CMHCs would "eliminate the need for mental institutions" and would provide individuals with chronic mental illness a better quality of life (Barusch, 2002).

At the state level, additional laws were passed in the 1960s and 1970s that made it more difficult to involuntarily detain persons with mental illness (Jencks, 1994; Seager, 1998). California's Lanterman-Petris-Short Act of 1967 (Cal. Welf. \& Inst. Code $§ 5000$, et seq), known as the LPS Act, was one of the first of these new laws and it served as a model for similar laws enacted in other states (Seager, 1998). These laws put end to the indefinite commitment of mentally ill individuals by specifying clear guidelines for when and for how long it would be appropriate to involuntarily detain an individual (p.26). Being diagnosed with a mental illness or acting in a bizarre manner were no longer sufficient cause for detainment. According the LPS Act, to meet involuntary hospitalization criteria, an individual would need to present an imminent danger to self or others, or be "gravely disabled" (Cal. Welf. \& Inst. Code § 5150). "Gravely disabled" is defined as "a condition in which a person, as a result of a mental disorder, is unable to provide for his or her basic personal needs for food, clothing or shelter" (Cal. Welf. \& Inst. Code $\S 5008$ ). If an individual meets one or more of these criteria, he or she can be detained and evaluated for 72 hours and then his or her case is brought before a judge 
who determines if the individual requires further hospitalization (Cal. Welf. \& Inst. Code $\S 5151)$.

Unfortunately, at this same time when mental health patients were being discharged under newly implemented involuntary treatment guidelines, the enthusiasm for the creation of CMHCs began losing momentum before they could be fully established as originally planned (Padgett et al., 2006). Only about half of the proposed CMHCs were built (Kelley, 1998). Of these, few were equipped to provide services for persons with SMI (Barusch, 2002; Padgett et al., 2006). President Carter, in an attempt to facilitate renewed commitment for the provision of community mental health services, promoted the creation of a new mental health act called the Mental Health Systems Act of 1980 (42 U.S.C. § 9401, et seq; Goldman, 1999). This law had minimal impact and was essentially repealed a year later with the passage of the Omnibus Budget Reconciliation Act of 1981 (42 U.S.C. § 9902, et seq; Grob, 2000). Signed into law by President Reagan, the primary goal of this Act was to reduce federal spending, including funding for mental health services (p.9). By the time this Act became law, the modern American homeless crisis had already begun to unfold. This occurred as the nation's attention was focused on several other crises including fuel shortages, American hostages in Iran, and stagflation.

Even with the closure of state psychiatric hospitals and the failure of the CMHCs to materialize, large-scale homelessness among persons with SMI would probably not have emerged as a major social problem in the United States. There was one more key 
factor required to make this social problem a reality. This was an affordable housing shortage.

Up until the late 1970s, inexpensive housing, though often of substandard quality, made it possible for persons with SMI receiving disability benefits or small contributions from families to afford housing in the community. Single-Room Occupancy (SRO) buildings housed many low-income single adults, including poor persons with mental illness (Hopper, 2003). However, over time this affordable housing option began to disappear. Between 1973 and 1993, an estimated two million SRO units and other lowrent units were eliminated from the housing market as a result of abandonment and gentrification (Cohen, 2001). Making matters worse, there was very little new lowincome housing created during this period. During the last few decades HUD's budget dropped 65\%, from \$83 billion in 1978 to \$29 billion in 2006 (Western Regional Advocacy Project, 2006). When adjusted for inflation, the original $\$ 83$ billion would be equal to about $\$ 250$ billion in 2006 , meaning that these cuts are actually much greater than the raw numbers would suggest. With the elimination of existing SRO housing and cutbacks in federal spending to create new housing, low-income single adults had fewer housing options and, therefore, had an increased likelihood of becoming homeless.

The Reagan administration, in office from 1981 to 1989, was slow to respond to the emerging homeless crisis in American cities. This administration was "reluctant to admit that homelessness constituted a public problem" and "when forced to respond, it treated homelessness as a temporary emergency" (Katz, 2001, p.133). However, by the mid-1980s, this perception began to change as policymakers started to accept that large- 
scale homelessness was not the temporary problem they assumed it was a few years earlier. They responded with the passage of the Stewart B. McKinney Homeless Assistance Act of 1987 (42 U.S.C. $§ 11302$, et seq.).

McKinney Act was the first and only comprehensive federal legislation to directly address homelessness in the United States (National Coalition for the Homeless, 2010; SAMHSA, 2003b). This Act resulted in significant increases in federal spending on projects related to homelessness (Hopper, 2003). The primary focus of this Act was on housing as an intervention to homelessness therefore the U.S. Department of Housing and Urban Development (HUD) was given the task of administering the programs associated with this Act (HUD, 2012).

HUD began actively working to reduce homelessness in the United States in 1987 following passage of the McKinney Act (HUD, 2012). HUD currently administers several major programs that are designed to assist individuals who are homeless or about to become homeless including the Emergency Solutions Grants Program, the Supportive Housing Program, and the Shelter Plus Care Program. The Emergency Solutions Grants Program provides funding for street outreach, emergency shelter, and housing relocation and stabilization services. The Supportive Housing Program provides funding for the construction of and operating costs of supportive housing projects. The Shelter Plus Care Program provides homeless individuals with housing vouchers while at the same time requiring its participants to be enrolled in community mental health services. 
Running head: RISK FACTORS FOR HOMELESSNESS AMONG MENTAL HEALTH PATIENTS

Passage of the McKinney Act also led to the creation of the Interagency Council on Homelessness. This council was established to provide the nation with federal leadership on activities related to the assistance of homeless persons (U.S. Interagency Council on Homelessness, 2012).

Also in 1987, as it became apparent that a large percent of homeless persons were veterans of the armed services, an estimated $23 \%$ of the homeless population (Burt et al., 1999), the Department of Veterans Affairs (VA) began offering direct services to homeless veterans. The VA currently provides a range of specialized services to military veterans similar to those provided by other homeless service providers. These include street outreach, clinical assessment and referral for treatment of physical and psychiatric disorders, case management, employment assistance, and permanent supportive housing (Department of Veterans Affairs, 2012).

In addition to HUD and the VA, other government agencies that are involved in homelessness intervention and prevention include the Substance Abuse and Mental Health Services Administration (SAMHSA) and the U.S. Social Security Administration (SSA). SAMHSA supports homeless individuals with SMI by providing grant funding for community-based outreach, mental health, substance abuse, and case management services (SAMHSA, 2012) as well as funding for supportive housing services (Bassuk et al., 2010).

SSA has been directly and indirectly involved in assisting homeless persons with SMI. Two of the primary benefits programs administered by SSA are Supplemental 
Security Income (SSI) and Social Security Disability Insurance (SSDI). When these programs were created they helped make it possible for persons with SMI to live in the community by providing them with regular monthly cash benefits that could be used toward rent, food, clothing, and transportation (Rossi, 1989). Many homeless persons with SMI are SSI or SSDI recipients or would be eligible for these benefits if they were to apply. In response to the concern that some homeless persons with SMI were unable to successfully navigate the hurdles of the SSI or SSDI application process, SSA ran a demonstration program called the Homeless Outreach Projects and Evaluation (HOPE) from 2003 to 2009 (U.S. Social Security Administration, 2012). HOPE provided community-based mental health organizations with funding for outreach services that helped eligible homeless persons apply for SSI or SSDI. An evaluation of this project found that homeless persons with disabilities who had assistance from HOPE program staff with filing applications for benefits received SSA determination decisions sooner than participants in the usual services comparison group and at 12 months from time of intake HOPE enrollees were less likely to be homeless than they were at time of intake (McCoy, Robins, Bethel, Tornow, \& Frey, 2007).

George Herbert Walker Bush's administration, in office from 1989 to 1993, supported some additional funding for homeless programs, however significant Executive Branch support for homeless programs did not occur until Bill Clinton became president in 1993 (Burt et al., 2001). The Clinton administration, in the White House from 1993 to 2001, showed more interest in addressing homelessness than the previous two administrations. During this period funding for homeless programs was increased and 
the focus began to switch from temporary to longer-term solutions (Katz, 2001). For example, HUD, which during the Reagan administration saw increasing emergency shelter as its priority, now began to concentrate its efforts on increasing the availability of transitional and permanent housing (p.134). During Clinton's first year in office he used executive powers to order the Interagency Council on Homelessness to come up with a federal plan for ending homelessness. This plan, called the Continuum of Care, helped move the federal government in the direction of long-term strategizing regarding the homelessness problem. The Clinton administration recognized that adding more shelter beds would not end homelessness. Instead, coordinated services on a continuum from emergency shelter to transitional housing and specialized services including chemical dependency treatment would be required (Burt et al., 2001). An essential first step in figuring out how to better coordinate services between homeless providers was to get a better understanding of who they were and who they served. To accomplish this goal the federal government funded a major study in 1996 called the National Survey of Homeless Assistance Providers and Clients (Burt et al., 1999).

George Walker Bush's administration, in office from 2001 to 2009, publically endorsed the concept of ending chronic homelessness in ten years through regional planning and encouraged cities and counties to create their own regionally focused 10year plans to end homelessness (U.S. Interagency Council on Homelessness, 2008). While the Bush administration made modest increases in funding for some homeless assistance programs, it cut funding for other low-income housing assistance programs and as a result local and state governments were left struggling to acquire the resources 
needed to successfully implement their 10-year plans (Rice \& Sard, 2007). For example, HUD’s budget decreased from $\$ 31.3$ billion in 2004 to $\$ 28.5$ billion in 2006, resulting in the loss of approximately 150,000 housing vouchers (p.3).

The concept of the 10-year plan, first articulated by the National Alliance to End Homelessness in 2000, gained ground quickly and by 2010 more than 243 cities, counties, and states had created their own plans to end homelessness (National Alliance to End Homelessness, 2012). To succeed these 10-year plans will require significant federal financial support, which was not received during the Bush years. Although federal spending on homeless programs has increased slightly since Barack Obama became president in 2009 and new legislation with new emphasis on homeless prevention called the Homeless Emergency Assistance and Rapid Transition to Housing (HEARTH) Act was signed into law in later this same year, homelessness continues to be a major problem in the United States.

This review of the general literature on homelessness helps illustrate a social problem of significant magnitude that directly or indirectly affects hundreds of thousands of people across the United States on any given day. The literature on characteristics and risk factors provides a general description about who these individuals are, which groups are over-represented, and who is most at risk for becoming homeless. The consequences resulting from homeless are then described. Lastly, a discussion of the historical and political context related to widespread homelessness is presented. This describes the emergence of social problem that a nation was ill prepared to deal with. Then later, as the nation became more knowledgeable about this problem, new policies were enacted 
that better addressed the root causes of this problem. However, despite the efforts made, large scale homelessness among persons with SMI continues.

\section{Review of the Relevant Treatment Literature}

This review of the relevant treatment literature examines intervention approaches

that have been employed to assist individuals with SMI experiencing homelessness. This section includes literature on effective interventions, cost-effectiveness analysis, and the relationship between length of treatment and patient outcomes.

\section{Effective Interventions: Does Anything Work?}

Over the past few years a variety of interventions have been used to address the problem of homelessness among persons with SMI. Supportive housing, innovative shelter programs, assertive community treatment, and intensive case management approaches are among the more frequently mentioned interventions to appear in the literature on this topic (Nelson et al., 2007).

A review of the literature shows that several innovations designed specifically for homeless persons with SMI are effective at either reducing homelessness among persons with SMI or reducing the social costs associated with these individuals such as reduced frequency of incarceration and hospitalization. Among the more effective programs are those that provide housing first and supervised living as opposed to treatment first options which require treatment progress as a condition of housing (Mueser, Noordsy, Drake, \& Fox, 2003; Padgett et al., 2007). 
Tsemberis, Gulcur and Nakae (2004) examined the long-term effects of the Housing First approach, a model developed by Pathways to Housing in New York City. The Housing First model, designed to address the problem of chronic homelessness, views housing as a basic right of every individual regardless of sobriety or medication compliance (p. 651). Programs utilizing this approach do not require successful completion of any intermediate steps as a condition for placement into permanent housing. The study utilized an experimental design in which 225 participants were randomly assigned to housing either immediately as needed (i.e. experiment group) or contingent on sobriety criteria (i.e. comparison group). The results indicated that during a 2-year follow-up period the experiment group obtained housing earlier $(\mathrm{F}=27.7, \mathrm{p}<$ $.001)$ and spent less time homeless $(\mathrm{F}=10.1, \mathrm{p}<.001)$ than the comparison group (p.653).

A Canadian study by Podymow, Turnball, and Coyle (2006) describes an innovative shelter-based harm reduction program for homeless persons with alcohol dependence called the Managed Alcohol Program (MAP). Close supervision was provided to help these individuals minimize harmful effects of their substance use. The most unique feature of this program was that participants were provided alcohol on-site. Participants could have up to 5 ounces of wine or 3 ounces of sherry per hour, from 7 AM to 10 PM, seven days a week. For the 17 participants in the study, emergency department visits dropped significantly from an average of .79 visits per month during the three years prior to receiving the MAP intervention to .51 visits while participating in MAP. Police encounters also dropped significantly, from 1.07 to .52 per month. In 
addition, 11 of the 17 participants reported they decreased their alcohol consumption after entering this program. While the results are promising, it is important to note this study had a limited sample.

Case management is a "key ingredient" in many local, state, and federal efforts to provide essential services to people experiencing homelessness (Morse, 2004). Homeless individuals tend to have a variety of unmet service needs and face numerous barriers to obtaining services within a "fragmented" service system (p.46). The role of case managers working with these individuals is to assist these individuals in obtaining needed services by overcoming barriers and coordinating services between multiple service providers.

There are a variety of case management approaches currently being used to assist homeless persons with SMI. With most approaches, the case manager is responsible for "establishing and maintaining a therapeutic relationship with a client on a continuing basis, whether the client is in the hospital, in the community, or involved with other agencies" (Allness \& Knoedler, 2003). Assertive community treatment and intensive case management approaches are often used by agencies providing mental health services to homeless clients with SMI living in the community. Both of these approaches involve small staff to client ratios of about one staff for every 10 clients (Mueser et al., 2003). The main difference between these approaches is that assertive community treatment involves a multidisciplinary team working with a shared caseload, whereas the intensive case management approach involves clients assigned to individual case managers (Mueser et al.). Both of these approaches give case managers the ability to "provide the 
intensive response that is required to help homeless individuals stabilize and manage their lives" (Burt et al., 2002). This often includes a lot of direct one-on-one support, such as accompanying clients to psychiatric appointments and housing interviews. However, in many communities these more intensive approaches are not available to all who need them, and some homeless persons with SMI are served by community mental health programs using the more traditional broker case management model. The broker model is less intensive, more office-based, and usually involves caseloads of 50 or more (Morse, 2004). These case managers do less direct clinical service with clients and focus more on “service planning and referral and linkage" instead (p. 48).

Coldwell and Bender (2007) reviewed 10 studies on the effectiveness of assertive community treatment with homeless persons with SMI. Six of these were randomized controlled trials and four were observational studies. The results of this meta-analysis indicated that assertive community treatment is more effective than other case management models in reducing homelessness and psychiatric symptom severity. In the randomized trials, assertive community treatment clients experienced a $37 \%$ greater reduction in homelessness and a $26 \%$ greater improvement in psychiatric symptom severity compared to other case management models. In the observational studies, assertive community treatment clients attained a $104 \%$ reduction in homelessness and a $62 \%$ reduction in symptom severity compared with clients receiving standard case management services.

There is also evidence that intensive case management services have been effective at assisting homeless individuals with SMI. Shern et al. (2000) compared the 
outcomes of "street-dwelling" individuals with serious and persistent mental illness living in New York City who were randomly assigned to either an intensive case management program called Choices (i.e. experiment group) or who were referred to "standard services" (i.e. comparison group). The Choices client-to-staff ratio was 13:1. Staff within this program provided clients with outreach and engagement, individualized client-driven goal planning, assess to a drop-in center and respite housing, and assistance with obtaining and maintaining permanent housing in the community (p.1874). The results from the 24-month intervention period indicated significantly better outcomes for the clients receiving intensive case management services compared to the clients in the comparison group. At baseline, all of the participants were homeless and staying outside of shelters. At 24 months, $38 \%$ of the participants enrolled in the Choices program had obtained housing compared with $24 \%$ in the comparison group. Shern et al. explained that while $38 \%$ may seem low, it should be considered successful given the participants' initial reluctance to accept services and the difficulty of finding housing providers willing to accept individuals with SMI who have been living on the streets for long periods of time.

\section{Cost-Effectiveness Analysis}

Policymakers are often interested in more than whether or not a homeless intervention is effective; they also want to know if it cost-effective (Frisman, Corell, \& Hoburg, 2004). Many costs associated with homelessness are difficult to measure, therefore cost-benefits studies generally focus not on all costs but on the easier to measure costs such as costs associated with incarceration and psychiatric hospitalization. 
If it can be demonstrated that the costs associated with an intervention are equal to or less than the costs associated with not doing the intervention, then it can be argued that the intervention is cost-effective.

Culhane, Metraux, and Hadley (2001) evaluated the cost benefits of supportive housing for formerly homeless people. This study tracked 4,679 homeless people with psychiatric disabilities who were placed into supportive housing created by the $1990 \mathrm{New}$ York/New York Agreement to House Homeless Mentally Ill Individuals. The researchers first examined these individuals' use of emergency shelters, psychiatric hospitals, medical services, prisons and jails in the two years before and in the two years after they were placed in housing. They then compared their service utilization in these two time periods to the service utilization of comparison groups of homeless individuals with similar characteristics who had not been placed in homeless housing projects. The results suggested that homeless persons with SMI are "extensive users of publicly funded services, particularly inpatient health services, accumulating an average of $\$ 40,449$ per year in health, corrections and shelter system costs" (p. 28). The participants in the intervention group, once placed into supportive housing, reduced their use of publicly funded services by an average of $\$ 16,282$ per year. Thus, with the average annual cost per unit of supportive housing in New York City costing \$17,277, this savings was nearly enough to pay for the cost of supportive housing for these individuals.

Similar studies on the cost-effectiveness of supportive housing for homeless individuals have since been conducted in other cities including Denver, Colorado 
(Perlman \& Parvensky, 2006), and Portland, Oregon (Moore, 2006). Both these studies actually showed cost-savings of supportive housing.

\section{Service Retention and Length of Treatment}

Although no studies that specifically examine the relationship between community mental health service retention and homelessness appear in the literature, the general consensus in the treatment literature is that treatment retention is correlated with favorable results, for example, sobriety, decrease in recidivism, etc. It is also generally agreed that for clients who have both mental and substance use disorders, treatment retention and long-term treatment is of the essence (Mueser et al., 2003). However, being homeless can make retaining services more challenging. Marrero et al. (2005) examined factors associated with drug treatment dropout among injection drug users at a treatment facility in Puerto Rico. Of the 124 participants who entered the program within the timeframe of this study, $33(26.6 \%)$ dropped out prior to the completing treatment. A comparison between characteristics of participants who completed the program and those who dropped out revealed that homeless participants were over three times more likely to drop out than non-homeless participants $(\mathrm{OR}=3.32, \mathrm{p}=.03)$. The reasons for why participants dropped out where not reported.

A study by Brunette, Drake, Woods, and Hartnett (2001) presents evidence of the association between length of treatment and better patient outcomes. This study compared the outcomes of patients who completed long-term outpatient treatment with patients who completed short-term residential treatment. The two programs were run by 
the same treatment center and were designed to treat individuals with co-occurring mental health and substance use disorders. The duration of treatment was approximately two years for long-term and three to six months for short-term. The results of a comparison of six-month posttreatment outcomes for the 43 patients who completed the long-term program with the 39 patients who completed the short-term program indicated that patients in the long-term program were more likely to maintain abstinence $\left(X^{2}=10.4\right.$, $\mathrm{df}=1, \mathrm{p}<.001)$ and were less likely to experience homelessness $\left(X^{2}=4.2, \mathrm{df}=1, \mathrm{p}<\right.$ .05) compared to individuals who had short-term treatment.

\section{Summary}

This chapter included a review of the general literature on homelessness and an examination of the magnitude of the social problem. Characteristics of the homeless population, risk factors for homelessness, and individual and societal consequences of homelessness were discussed. Historical and political context related to homelessness among persons with SMI was also presented. In addition, a review of the relevant treatment literature was discussed. This included a discussion on effective interventions, cost-effectiveness studies, service retention, and effect of length of treatment on outcomes. The research methodology for this study is presented in the next chapter. 


\section{CHAPTER III}

\section{METHODOLOGY}

\section{Introduction}

As stated in Chapter One, the purpose of the study was to identify risk factors associated with homelessness among adults with SMI, assess the relationship between housing status and consumption of costly publicly funded resources, identify characteristics associated with service retention, and evaluate whether length of treatment for these individuals is associated with better patient outcomes. The methodology employed to test the research questions and hypotheses is presented in this chapter. This chapter is organized into the following sections: research design, participants and setting, study variables, data collection, protection of human subjects, and data analysis.

\section{Research Design}

The research conducted was exploratory. The study utilized a non-experimental retrospective cohort study design. It consisted of secondary data analysis of existing agency records over a 3-year period, from January 1, 2005 to December 31, 2007.

All SAGE patients who had active enrollment status from January 1, 2005 to December 31, 2005 were included in the sample. Outcomes for these participants were reviewed for an additional 24 months or until they left the program. The expected number of participants from the first 12-month period was approximately 500. It was estimated that approximately 300 to 400 of the original sample would continue to be 
enrolled in the program at the end of the third year. By including the entire patient population from a specific time period there was minimal risk of selecting a sample that was not representative of the overall patient population at this program and furthermore it maximized the sample size compared with what would have been obtained with a random sample.

This design enabled the researcher to answer all of the research questions asked in this study. The existing computerized agency dataset contained all of the data required for this. This design provided the researcher with the unique opportunity to analyze a large dataset with a large number of variables and a large sample size. This design also made it more feasible to examine a larger number of variables than many other designs because less time and resources were required for data collection and thus more energy could be used examining variables. Another advantage of this design is that it was nonintrusive. No participants in this study were subjected to lengthy and highly personal questionnaires or be placed in various experimental conductions.

\section{Participants and Setting}

The target population of the study was homeless and formerly homeless adults with SMI enrolled in outpatient mental health services at the Downtown Emergency Service Center's (DESC) SAGE mental health program. SAGE is an acronym that stands for Support Advocacy and Growth Enhancement. DESC, located in Seattle, Washington, is a nonprofit organization that specializes in providing comprehensive integrated services to homeless and formerly homeless adults. This organization utilizes the harm 
reduction approach in working with its patients as illustrated by their commitment provide housing and mental health services regardless of patients use of substances or refusal to take psychiatric medication. Treatment is based on the principles of motivational enhancement as described above. The staff are trained in both harm reduction principles and motivational interviewing techniques.

DESC was established in 1979 in response to the sudden increase in homelessness that occurred in Seattle and many other cities in the United States in the late 1970s. Seattle is a large urban Northwest port city located in King County, Washington with a population of approximately half a million residents (U.S. Census Bureau, 2010). According to the "One Night Count" taken on January 25, 2008, there were at least 8,439 homeless people in King County, with most living in Seattle (Seattle-King County Coalition for the Homeless, 2008).

DESC began as an emergency shelter provider, operating a 200 bed overnight shelter for single adults in the ballroom of an old hotel. During the 1980s and 1990s, DESC expanded its services for homeless persons to include outpatient mental health services and supportive housing (Burt et al., 2004). Its mental health services are funded primarily with Medicaid reimbursements and its housing projects and shelter are mostly funded with federal grants from HUD's Supportive Housing Program. At the time of this study DESC operated about 500 units of supportive housing in six buildings in addition to its original shelter and it had about 1000 patients enrolled in three outpatient mental health programs. Only patients enrolled in the largest of these outpatient programs, SAGE, with about 700 patients, were included in the study. 
DESC in recent years has been gaining national recognition for its work with homeless and formally homeless adults. In 2003, this organization was selected by the U.S. Department of Health and Human Services to receive the Exemplary Program Award (SAMHSA, 2003a). In addition to this, DESC's 1811 Eastlake housing project has been the focus of several research articles. Even though the residents of this project were allowed to continue drinking alcohol their overutilization of costly public services such as emergency room and jail visits decreased (Larimer et al., 2009) as did the amount of alcohol they consumed (Collins et al., 2012).

DESC's long-term outpatient mental health program, SAGE, which has been serving patients since 1996, provides state-licensed mental health treatment to individuals diagnosed with DSM-IV-TR Axis I mental health disorders and is funded primarily with Medicaid reimbursements though a small number of patients self-pay. At the time of the study, SAGE had a staff of about 30 that included case managers, intake specialists, clinical supervisors, nurses, and a full-time psychiatrist. SAGE utilized an intensive case management approach with patients assigned to individual case managers who had caseloads ranging from 15 to 35 . Caseload size was determined by the level of functioning of the patients on each caseload.

\section{Study Variables}

The study examined the following independent variables:

- Age: this was tabulated in years and was determined by subtracting the date of birth of each patient from 12/31/05, 12/31/06, and 12/31/07. 
- Gender: categories included (1) male, (2) female, (3) transgender male to female, or (4) transgender female to male. However, analysis was restricted to male and female as the sample size of the transgender categories were too small.

- Race/ethnicity: (1) African American or African descent, (2) American Indian or Alaska Native, (3) Asian or Pacific Islander, (4) White/non-Hispanic, (5) Latino or Hispanic, (6) multi-racial, or (7) other.

- Income amount: total gross annual income amount in dollars on 12/31/05, 12/31/06, and 12/31/07.

- Months of enrollment: number of months of enrollment in SAGE program on 12/31/05, 12/31/06, and 12/31/07.

- DSM-IV-TR Axis I mental health or substance use disorder(s): DSM-IV-TR coding category ranging from 290-319 with each code indicating a specific disorder.

- Housing status during a 12 month period: (0) one or more episodes of homelessness, or (1) no episodes of homelessness from 1/1/05 to 12/31/05, $1 / 1 / 06$ to $12 / 31 / 06$, and $1 / 1 / 07$ to $12 / 31 / 07$.

The study examined the following dependent variables:

- SAGE service hours during a 12 month period: amount of SAGE service hours received by each patient from $1 / 1 / 05$ to $12 / 31 / 05,1 / 1 / 06$ to $12 / 31 / 06$, and $1 / 1 / 07$ to $12 / 31 / 07$. 
- Housing status during a 12 month period: (0) one or more episodes of homelessness, or (1) no episodes of homelessness from 1/1/05 to 12/31/05, $1 / 1 / 06$ to $12 / 31 / 06$, and $1 / 1 / 07$ to $12 / 31 / 07$.

- Jail days during a 12 month period: number of days in jail from 1/1/05 to $12 / 31 / 05,1 / 1 / 06$ to $12 / 31 / 06$, and $1 / 1 / 07$ to $12 / 31 / 07$.

- Psychiatric hospitalization days during a 12 month period: number of days of psychiatric hospitalization from $1 / 1 / 05$ to $12 / 31 / 05,1 / 1 / 06$ to $12 / 31 / 06$, and $1 / 1 / 07$ to $12 / 31 / 07$.

- DSM-IV-TR Global Assessment of Functioning score (GAF) on 12/31/05, 12/31/06, and 12/31/07: scale ranging from 0 to 100 . This scale is considered moderately reliable with an intraclass correlation coefficient (ICC) of .86 (Hilsenroth et al., 2000).

- Service retention: (0) patient exited program, or (1) patient continued enrollment from $1 / 1 / 05$ to $12 / 31 / 05,1 / 1 / 06$ to $12 / 31 / 06$, and $1 / 1 / 07$ to 12/31/07.

\section{Data Collection}

The study utilized existing agency records. These records were recorded by agency staff as part of their regular work duties and are stored on a computerized database in spreadsheet format. At the request of the researcher, agency staff created an electronic copy of the SAGE patient database with identifiers removed that included the records of 380 patients on 33 existing variables. The data was then imported into SPSS. 


\section{Protection of Human Subjects}

Special precautions were taken to minimize the likelihood that the study would result in negative consequences for the patients whose data was used for the study, either directly or indirectly including: physical, social, psychological, legal, economic or other risks such as discomfort or inconvenience. The study utilized existing agency data and no other data were collected, therefore the only possible risk of harm to patients was if their confidential health information had been accidentally released.

Several safeguards were adopted to prevent any possibility of harm to the patients. To protect the confidentiality of the patients, identifiers were removed from the data prior to the transfer of the data from the agency staff to the researcher. The identifiers that were removed included the participants' names and Social Security numbers. The agency maintains an electronic copy of the original data, still containing the identifiers, on a password protected agency computer so it will be possible to validate the data if needed at a later date using a coded ID system. Once the study is completed the agency will delete the ID codes from the data to prevent an accidental breach of confidentiality.

The study, due to its exclusive use of secondary data, did not require a HSRRC review. The following four HSRRC criteria for "Review Not Required" were met prior to the start of the study:

- All identifying information has been removed and data cannot be linked back to individuals; 
Running head: RISK FACTORS FOR HOMELESSNESS AMONG MENTAL HEALTH PATIENTS

- No contact with subjects was involved;

- Data had been previously collected by another investigator;

- Data already existed

\section{Data Analysis}

Descriptive statistics, multiple logistic regression, hierarchical multiple regression, two-way repeated measures analysis of variance (ANOVA), and Cochran's Q test were used to analyze the study data.

Descriptive statistics including frequencies, percentages, and averages were used to describe patient characteristics. Frequencies and percentages were used to describe the following qualitative variables: gender, race/ethnicity, source of primary income, Axis I mental health disorders, Axis I substance use disorders, co-occurring disorders, and housing status. Means were used to describe the following quantitative variables: age, annual income, number of months enrolled in SAGE program, GAF scores, number of days in jail in the past year, number of days in psychiatric hospital in the past year, and number of service hours with SAGE in the past 12 months.

Research Question 1 concerning patient risk factors associated with homelessness was answered using multiple logistic regression analysis. This procedure was conducted to determine to what degree the predictor variables - age, gender, race, income, DSM-IVTR Axis I disorder(s), and DSM-IV-TR GAF scores—predicted the binary response variable housing status (homeless or not homeless). This analysis was conducted for a 3 year period of time from January 1, 2005 to December 31, 2007. For ethnicity and 
diagnosis, counts of patients by subgroup were examined and participants were grouped into meaningful categories with adequate group sizes to allow analysis. For example, the following new variables were created from recoding the existing variables:

- Major depressive disorder: (1) diagnosed with major depression, or (0) not diagnosed with major depression.

- Co-occurring disorders: (1) DSM-IV-TR Axis I mental health disorder and substance use disorder, or (0) Axis I mental health disorder only.

Research Question 2 concerning patients' use of community resources based on housing status was answered using hierarchical multiple regression. This analysis was conducted to assess the degree to which the predictor variable housing status, controlling for gender, race, and DSM-IV-TR Axis I disorder(s), was linearly related to the quantitative response variables number of days in jail, number of days in the psychiatric hospital, and SAGE service hours during a 3 year period from January 1, 2005 to December 31, 2007.

Research Question 3 concerning the patient characteristics associated with service retention was answered using multiple logistic regression analysis. This procedure was conducted to determine to what degree the predictor variables-housing status, age, gender, race, income, DSM-IV-TR Axis I disorder(s), DSM-IV-TR GAF scores, and months of enrollment - predicted the binary response variable service retention (patient exited program or continued enrollment). This analysis was conducted for a 3 year period of time from January 1, 2005 to December 31, 2007. 
Research Question 4 concerning the relationship between length of enrollment and patient outcomes was answered using two-way repeated measures ANOVA and Cochran's Q test. Four separate two-way repeated measures ANOVA tests were conducted, one for each quantitative outcome variable (i.e. number of days in jail, number of days of psychiatric hospitalization, SAGE service hours, and DSM-IV-TR GAF scores), to evaluate the relationship between race and substance use and patient outcomes over a 3 year period. The within-subjects factor was enrollment year with three levels $(2005,2006$, and 2007). The analysis also included two between-subjects factors that were created by recoding race/ethnicity, DSM-IV-TR Axis I disorder(s), and housing status variables into a single new dichotomous dummy variable. This new variable was:

- African American with substance use disorder and one or more episodes of homelessness during the 3-year study period: (1) African American with substance use disorder, and homeless episodes, or (0) non-African American, not diagnosed with substance use disorder, and no homeless episodes.

The Cochran's Q test was used to evaluate whether housing status improved over time for patients enrolled in the SAGE program. The independent variable for this analysis was enrollment year (2005, 2006, and 2007) and the dichotomous dependent variable was housing status (homeless and not homeless). Separate tests were conducted for patients of different demographic and diagnostic categories to assess whether housing status over time improved for patients regardless of gender, race, or diagnosis. 


\section{Summary}

This chapter provided a detailed description of the research plan for the study. The purpose for the research was restated, followed by a discussion of the research design. The target population was defined and the method used for selecting the participants was described. The study variables were listed and defined and the data collection procedures were discussed. In addition, the strategy used to protect human subjects was discussed. Finally, the methods for data analysis for each of the four research questions were presented. The results of the data analysis are presented in the following chapter. 


\section{CHAPTER IV}

\section{PRESENTATION AND ANALYSIS OF DATA}

\section{Introduction}

This chapter presents the results of the data analysis for the four research questions and hypotheses of this study. Descriptive statistics are first presented followed by the results of the bivariate and multivariate analysis. The presentation of the findings is arranged by research question and hypothesis. Multiple logistic regression was used to answer the first and third research questions and hypotheses. Hierarchical multiple regression was used to answer the second research question and hypothesis, and two-way repeated measures ANOVA and Cochran's Q test were used for the final research question and hypothesis.

\section{Descriptive Statistics}

Of the 550 mental health patients who were enrolled in the SAGE Program on January 1, 2005, 380 had continuous enrollment this entire year and therefore met the inclusion criteria of the study. These patients formed the cohort for the study. At the start of 2005, the mean length of enrollment for these patients was approximately three years and ranged from 11 days to 8.2 years. Of these patients, 312 had continuous enrollment during 2006 and 271 had continuous enrollment during 2007. Approximately $82 \%$ of the study cohort retained services during the second year of the study and $71 \%$ of the original cohort were still enrolled at the end of the third year. 
The mean age of SAGE patients in the study cohort on December 31, 2005 was 47 years old. From 2005 to 2007, the gender makeup of the cohort remained relatively stable at approximately two-thirds male and one-third female. Table 1 reports mean age of the study cohort over a 3-year period and Table 2 reports frequencies and percentages by gender over a 3-year period.

Table 1

Descriptive Statistics for Age, Income Amount, and GAF

\begin{tabular}{lrrrrrr}
\hline & \multicolumn{2}{c}{2005} & \multicolumn{2}{c}{2006} & \multicolumn{2}{c}{2007} \\
\cline { 2 - 7 } & $\mathrm{M}$ & \multicolumn{1}{c}{ SD } & \multicolumn{1}{c}{ M } & \multicolumn{1}{c}{ SD } & \multicolumn{1}{c}{ M } & \multicolumn{1}{c}{ SD } \\
\hline Age & 47.35 & 9.29 & 48.47 & 9.34 & 49.63 & 9.37 \\
Annual income amount & $\$ 6817$ & $\$ 2061$ & $\$ 7357$ & $\$ 1869$ & $\$ 7872$ & $\$ 1868$ \\
GAF score & 43.37 & 8.04 & 43.21 & 8.10 & 43.14 & 8.27 \\
\hline
\end{tabular}

In $2005,56 \%$ of the cohort was non-Hispanic White. The other $44 \%$ of the sample was comprised patients who were members of racial or ethnic minority groups, the largest of which was African America at about 25\%. A higher dropout rate among African American patients, approximately twice that of Whites, resulted in the percentage of Whites increasing about two percentage points from 2005 to 2007 , while the percentage of African Americans decreased about three points during this same period.

Table 2 reports the frequencies and percentages associated with gender and race characteristics of the study cohort over a 3-year period. 
Table 2

Descriptive Statistics Gender and Race

\begin{tabular}{lrrrrrr}
\hline & \multicolumn{2}{c}{2005} & \multicolumn{2}{c}{2006} & \multicolumn{2}{c}{2007} \\
\cline { 2 - 7 } Characteristic & $\mathrm{N}$ & $\%$ & $\mathrm{n}$ & $\%$ & $\mathrm{n}$ & $\%$ \\
\hline Gender & & & & & & \\
Male & 253 & 66.6 & 203 & 65.1 & 177 & 65.3 \\
Female & 124 & 32.6 & 106 & 34.0 & 91 & 33.6 \\
Transgender male-to-female & 2 & 0.5 & 2 & 0.6 & 2 & 0.7 \\
Transgender female-to-male & 1 & 0.3 & 1 & 0.3 & 1 & 0.4 \\
Race & & & & & & \\
White/non-Hispanic & 213 & 56.1 & 181 & 58.0 & 158 & 58.3 \\
African American & 95 & 25.0 & 67 & 21.5 & 59 & 21.8 \\
Latino/Hispanic & 33 & 8.7 & 27 & 8.7 & 25 & 9.2 \\
American Indian & 18 & 4.7 & 17 & 5.4 & 16 & 5.9 \\
Multi-racial/other & 17 & 4.4 & 16 & 5.1 & 11 & 4.1 \\
Asian/Pacific Islander & 4 & 1.1 & 4 & 1.3 & 2 & 0.7 \\
\hline
\end{tabular}

The vast majority of SAGE patients, more than $80 \%$, received either SSI or SSDI as their primary source of income. A smaller number of clients, $16 \%$ or fewer, received Washington State GA-X benefits. The percentage of patients with either no income or income from another source was less than $3 \%$. The mean income amount increased from $\$ 6817$ in 2005 , to $\$ 7357$ in 2006 , and to $\$ 7872$ in 2007 . This increase was due in part to annual cost of living increases as well as patients moving from state to federal cash benefit programs that pay more. Table 3 reports the frequencies and percentages associated with income source over a 3-year period and Table 1 reports mean income amount during the same period. 
Table 3

Descriptive Statistics for Income Source

\begin{tabular}{lrrrrrr}
\hline \multirow{2}{*}{ Primary income source } & \multicolumn{2}{c}{2005} & \multicolumn{2}{c}{2006} & \multicolumn{2}{c}{2007} \\
\cline { 2 - 7 } SSI & \multicolumn{1}{c}{$\%$} & \multicolumn{1}{c}{ n } & \multicolumn{1}{c}{$\%$} & \multicolumn{1}{c}{$\%$} \\
SSDI & 193 & 50.8 & 170 & 54.7 & 152 & 56.3 \\
GA-X & 116 & 30.5 & 103 & 33.1 & 98 & 36.3 \\
Other/no income & 62 & 16.3 & 29 & 9.3 & 14 & 5.2 \\
\hline
\end{tabular}

Approximately $99 \%$ of 380 patients in the study cohort had histories of homelessness prior to 2005. From 2005 to $2007,46 \%$ of SAGE mental health patients in the study cohort experienced one or more episodes of homelessness. In 2005, approximately $42 \%$ of the study cohort experienced homelessness. However, the percentage of patients experiencing homelessness decreased steadily over the next two years. By 2007, the percentage of patients experiencing homelessness had dropped by half to $21 \%$. Table 4 reports frequencies and percentages associated with housing status over a 3-year period.

Table 4

Descriptive Statistics for Housing Status

\begin{tabular}{lrrrrrr}
\hline & \multicolumn{2}{c}{2005} & \multicolumn{2}{c}{2006} & \multicolumn{2}{c}{2007} \\
\cline { 2 - 7 } Housing status & $\mathrm{n}$ & \multicolumn{1}{c}{$\%$} & $\mathrm{n}$ & $\%$ & $\mathrm{n}$ & $\%$ \\
\hline No homeless episodes & 219 & 57.6 & 222 & 71.2 & 213 & 78.6 \\
Experienced episodes of homelessness & 161 & 42.4 & 90 & 28.8 & 58 & 21.4 \\
\hline
\end{tabular}

The study cohort had a mean DSM-IV-TR GAF score of 43 for each of the three years of the study. Lower scores indicate lower functioning and scores in the 41 to 50 range indicate serious mental health symptoms or serious impairment in social, occupational, or school functioning (American Psychiatric Association, 2000). 
All of the patients in the study cohort were diagnosed with at least one DSM-IV-

TR Axis I mental health diagnosis and many were diagnosed with more than one.

Approximately $50 \%$ of these patients were diagnosed with a mood disorder, $43 \%$ had schizophrenia or other psychotic disorder, and $22 \%$ had an anxiety disorder. The specific disorders that were most prevent were major depressive disorder, schizophrenia, and posttraumatic stress disorder. Table 5 reports the frequencies and percentages associated with each of the specific mental health diagnoses.

\section{Table 5}

Descriptive Statistics for Mental Health Disorders

\begin{tabular}{lrr}
\hline & \multicolumn{2}{c}{2005} \\
\cline { 2 - 3 } DSM-IV-TR Axis I mental health disorder & $\mathrm{n}$ & $\%$ \\
\hline Major depressive disorder & 103 & 28.7 \\
Schizophrenia & 67 & 17.6 \\
Posttraumatic stress disorder & 35 & 9.2 \\
Schizoaffective disorder & 26 & 6.8 \\
Bipolar I disorder & 25 & 6.6 \\
Depressive disorder NOS & 20 & 5.3 \\
Psychotic disorder NOS & 14 & 3.7 \\
Mood disorder NOS & 11 & 2.9 \\
Bipolar disorder NOS & 10 & 2.6 \\
Bipolar II disorder & 9 & 2.4 \\
Panic disorder & 8 & 2.1 \\
Anxiety disorder NOS & 8 & 2.1 \\
Dysthymic disorder & 7 & 1.8 \\
Generalized anxiety disorder & 5 & 1.3 \\
Delusional disorder & 2 & 0.5 \\
Dementia & 2 & 0.3 \\
Adjustment disorder & 1 & 0.3 \\
Eating disorder NOS & 1 & 0.3 \\
Obsessive-compulsive disorder & 1 & \\
\hline
\end{tabular}


Fifty-three percent of the SAGE patients in the study cohort were diagnosed with both a mental health disorder and a co-occurring substance use disorder. Of the seven different substance use categories identified, the most prevalent were alcohol abuse or dependence and cocaine abuse or dependence. Table 6 reports the frequencies and percentages associated with each of the substance use categories.

\section{Table 6}

Descriptive Statistics for Substance Use Disorders

\begin{tabular}{lrc}
\hline & \multicolumn{2}{c}{2005} \\
\cline { 2 - 3 } Substance use disorders & \multicolumn{1}{c}{$\mathrm{n}$} & \multicolumn{1}{c}{$\%$} \\
\hline Alcohol abuse or dependence & 47 & 12.4 \\
Cocaine abuse or dependence & 35 & 9.2 \\
Polysubstance dependence & 25 & 6.6 \\
Opioid abuse or dependence & 6 & 1.6 \\
Amphetamine abuse or dependence & 4 & 1.1 \\
Cannabis abuse or dependence & 1 & 0.3 \\
Sedative, hypnotic, or anxiolytic abuse or dependence & & \\
\hline
\end{tabular}

From 2005 to 2007 , approximately $32 \%$ of the SAGE patients in the study cohort were incarcerated one or more times and about $10 \%$ were psychiatrically hospitalized one or more times. During this 3-year period, patients' mean number of days in jail per year decreased from 7.44 days in 2005 to 2.72 days in 2007. Patients' mean number of days of psychiatric hospitalization remained relatively unchanged at approximately one day per year across all three years of the study. SAGE service hours dropped from approximately 44 hours per year in 2005 to 35 hours per year in 2007 . Table 7 reports mean and standard deviation for patient incarceration, psychiatric hospitalization, and SAGE service hours for this 3-year period. 
Table 7

Descriptive Statistics for Incarceration, Psychiatric Hospitalization, and SAGE Service Hours

\begin{tabular}{lrrrrrr}
\hline & \multicolumn{2}{c}{2005} & \multicolumn{2}{c}{2006} & \multicolumn{2}{c}{2007} \\
\cline { 2 - 7 } & \multicolumn{1}{c}{ M } & \multicolumn{1}{c}{ SD } & \multicolumn{1}{c}{ M } & \multicolumn{1}{c}{ M } & \multicolumn{1}{c}{ SD } \\
\hline Days incarcerated & 7.44 & 24.65 & 4.43 & 18.94 & 2.73 & 11.28 \\
Days of psychiatric hospitalization & 1.02 & 5.67 & 1.35 & 9.29 & 0.96 & 6.06 \\
SAGE service hours & 44.48 & 57.98 & 38.57 & 43.80 & 35.38 & 45.84 \\
\hline
\end{tabular}

\section{Testing the Research Questions and Hypotheses}

Inferential statistics were used to investigate the four research questions and hypotheses of this study. Logistic regression was used for the first research question and hypothesis to assess the relationship between patient characteristics and homelessness. Hierarchical multiple regression was used for the second research question and hypothesis to assess the relationship between housing status and patient utilization community resources. Logistic regression was used for the third research question and hypothesis to assess the relationship between patient characteristics and patient retention of outpatient mental health services. Lastly, two-way repeated measures ANOVA and Cochran's Q tests were used for the fourth research question and hypothesis to assess the relationship between length of time in mental health services and patient outcomes. The level of significance .05 was used for each statistical analysis used in this study.

\section{Research Question One}

Question 1: Among community mental health patients, which patient characteristics (i.e. age, gender, race, income, DSM-IV-TR Axis I disorder[s], and DSMIV-TR GAF score) are associated with episodes of homelessness when comparing patients who experienced homelessness with those who did not? Logistic regression was 
performed to assess the relationship between patient characteristics and the likelihood that they would experience one or more episodes of homelessness during a 3-year period. The model contained nine independent variables (age, gender, race, income amount, major depressive disorder, posttraumatic stress disorder, schizophrenia, substance use disorder, and Global Assessment of Functioning). The full model containing all predictors was statistically significant, $X^{2}(12, N=380)=59.56, p<.001$, indicating that the model was able to distinguish between patients who experienced homelessness and those that did not. The model as a whole explained between 14.5\% (Cox and Snell R square) and $19.4 \%$ (Nagelkerke R squared) of the variance in housing status, and correctly classified $67.1 \%$ of the cases. As shown in Table 8, four of the independent variables made a unique statistically significant contribution to the model (age, race, income amount, and substance use disorder). The strongest predictor of homelessness was African American race, with an odds ratio of 2.56. This indicated that African American patients were more than 2.5 times as likely to have experienced homelessness compared to non-Hispanic White patients, controlling for all other factors in the model. The second strongest predictor of homelessness was substance use disorder, with an odds ratio of 2.27. This indicated that patients diagnosed with a substance use disorder were also more than 2 times as likely to have experienced homelessness as patients not diagnosed with a substance use disorder. The odds ratio for income was 2.16 , indicating that patients with mean monthly incomes of less than $\$ 700$ were more than 2 times as likely to have experienced homelessness as patients with incomes of $\$ 700$ or higher, controlling for other factors in the model. The odds ratio of .96 for age was less than 1 , 
indicating that younger patients were more likely to have experienced homelessness than older patients. For every additional year of age patients were .96 times less likely to experience homelessness, controlling for other factors in the model. For additional detail on the results of this analysis see Table 8 . 
Table 8

Logistic Regression Predicting Likelihood of Homeless Episodes

\begin{tabular}{|c|c|c|c|c|c|c|c|c|}
\hline \multirow[t]{2}{*}{ Predictor } & \multirow[t]{2}{*}{$B$} & \multirow[t]{2}{*}{ S.E. } & \multirow[t]{2}{*}{ Wald } & \multirow[t]{2}{*}{$d f$} & \multirow[t]{2}{*}{$p$} & \multirow[t]{2}{*}{$\begin{array}{l}\text { Odds } \\
\text { Ratio }\end{array}$} & \multicolumn{2}{|c|}{$\begin{array}{c}95.0 \% \text { CI for } \\
\text { Odds Ratio }\end{array}$} \\
\hline & & & & & & & Lower & Upper \\
\hline Age & -0.04 & 0.01 & 10.26 & 1 & .001 & 0.96 & 0.94 & 0.98 \\
\hline \multicolumn{9}{|l|}{ Gender } \\
\hline Male & -0.24 & 0.25 & 0.94 & 1 & .33 & 0.79 & 0.48 & 1.28 \\
\hline Female & & & & & & 1.00 & & \\
\hline \multicolumn{9}{|l|}{ Race } \\
\hline African American & 0.94 & 0.28 & 11.75 & 1 & .001 & 2.56 & 1.50 & 4.39 \\
\hline American Indian & -0.14 & 0.54 & 0.06 & 1 & .80 & 0.87 & 0.31 & 2.50 \\
\hline Latino/Hispanic & -0.07 & 0.42 & 0.03 & 1 & .87 & 0.94 & 0.41 & 2.13 \\
\hline Other race & 0.50 & 0.49 & 1.02 & 1 & .31 & 1.64 & 0.63 & 4.28 \\
\hline $\begin{array}{l}\text { White/non- } \\
\text { Hispanic } \\
\text { Income }\end{array}$ & & & & & & 1.00 & & \\
\hline Less than $\$ 700$ & 0.77 & 0.34 & 5.04 & 1 & .025 & 2.16 & 1.10 & 4.23 \\
\hline$\$ 700$ or more & & & & & & 1.00 & & \\
\hline \multicolumn{9}{|l|}{ Major depression } \\
\hline Yes & -0.13 & 0.26 & 0.26 & 1 & .609 & 0.87 & 0.52 & 1.46 \\
\hline No & & & & & & 1.00 & & \\
\hline \multicolumn{9}{|l|}{ PTSD } \\
\hline Yes & -0.50 & 0.31 & 2.60 & 1 & 107 & 0.61 & 0.33 & 1.11 \\
\hline No & & & & & & 1.00 & & \\
\hline \multicolumn{9}{|l|}{ Schizophrenia } \\
\hline Yes & -0.54 & 0.29 & 3.57 & 1 & .059 & 0.58 & 0.33 & 1.02 \\
\hline No & & & & & & 1.00 & & \\
\hline \multicolumn{9}{|l|}{$\begin{array}{l}\text { Substance use } \\
\text { disorder }\end{array}$} \\
\hline Yes & 0.82 & 0.23 & 12.35 & 1 & $<.001$ & 2.27 & 1.44 & 3.58 \\
\hline No & & & & & & 1.00 & & \\
\hline GAF & 0.00 & 0.02 & 0.00 & 1 & .957 & 1.00 & 0.97 & 1.03 \\
\hline
\end{tabular}




\section{Hypothesis One}

Hypothesis 1: There is an association between patient characteristics (i.e. age, gender, race, income DSM-IV-TR Axis I disorder[s], and DSM-IV-TR GAF score) and housing status. The results of the logistic regression analysis support the hypothesis that there is an association between patient characteristics and homelessness for four of the independent variables (age, African American race, income amount, and substance use disorder). There was insufficient evidence to support this hypothesis for the other patient characteristics variables included in the model.

\section{Research Question Two}

Question 2: Do community mental health patients who experience episodes of homelessness consume more community resources (i.e. jail, psychiatric hospitalizations, and SAGE service hours) than patients who do not experience homelessness? This second research question was answered using hierarchical multiple regression. This was used to assess the ability of the variable housing status to predict patient community resource utilization, after controlling for the influence of other patient characteristics. Age, gender, White/non-Hispanic race, African American race, income, major depressive disorder, PTSD, schizophrenia, substance use disorder, and GAF were entered at Step 1, explaining $8.9 \%$ of the variance in incarceration, $5.7 \%$ of psychiatric hospitalization, and $17 \%$ of SAGE clinical service hours. After entry of housing status at Step 2 the total variance explained by the model as a whole for incarceration was $12.4 \%, F(11,368)=$ $4.73, p<.001$, psychiatric hospitalization was $5.9 \%, F(11,368)=2.11, p=.019$, and 
SAGE clinical service hours was $25.3 \%, F(11,367)=p<.001$. Housing status explained an additional $3.4 \%$ of the variance in incarceration, after controlling for the other patient characteristic variables, R squared change $=.03, F$ change $(1,368)=14.47$, $p<.001$. A non-significant $0.2 \%$ of the variance in psychiatric hospitalization was explained by housing status, after controlling for the other patient characteristic variables, R squared change $=.00, F$ change $(1,368)=.93, p=.335$. However, housing status explained an additional $8.3 \%$ of the variance in SAGE clinical service hours, after controlling for the other patient characteristic variables, $\mathrm{R}$ squared change $=.08, F$ change $(1,367)=40.70, p<.001$.

In the final model for incarceration, the control variable, housing status, was statistically significant (beta $=.20, p<.001)$, as were GAF (beta $=-.14, p<.008)$ and income $($ beta $=-.10, p=.041)$. In the final model for psychiatric hospitalization, the control variable, housing status, was non-significant (beta $=.05, p=.335$ ) and GAF was significant (beta $=-.13, p=.019$ ). In the final model for SAGE clinical service hours, the control variable, housing status, was statistically significant (beta $=.31, p<.001$, as was GAF (beta $=-.36, p<.001)$. For additional detail on the results of this analysis see Table 9. 
Table 9

Hierarchical Multiple Regression Analyses Predicting Community Resource Utilization From Housing Status

\begin{tabular}{|c|c|c|c|c|c|c|}
\hline \multirow[b]{3}{*}{ Predictor } & \multicolumn{6}{|c|}{ Type of community resource } \\
\hline & \multicolumn{2}{|c|}{ Incarceration } & \multicolumn{2}{|c|}{$\begin{array}{c}\text { Psychiatric } \\
\text { hospitalization }\end{array}$} & \multicolumn{2}{|c|}{$\begin{array}{c}\text { SAGE clinical service } \\
\text { hours }\end{array}$} \\
\hline & $\Delta R^{2}$ & B & $\Delta R^{2}$ & $\mathrm{~B}$ & $\Delta R^{2}$ & $\mathrm{~B}$ \\
\hline Step 1 & $.09 * * *$ & & $.06^{*}$ & & $.17 * * *$ & \\
\hline Age & & -.06 & & -.08 & & $-.10 *$ \\
\hline Gender & & .06 & & .01 & & .02 \\
\hline African American & & -.03 & & -.03 & & -.05 \\
\hline White/non-Hispanic & & -.11 & & .12 & & -.01 \\
\hline Income & & $-.13 * *$ & & -.06 & & -.06 \\
\hline Major depressive disorder & & -.02 & & -.02 & & -.01 \\
\hline PTSD & & -.04 & & -.05 & & -.03 \\
\hline Schizophrenia & & -.09 & & .00 & & .01 \\
\hline Substance use disorder & & $.11^{*}$ & & .09 & & .08 \\
\hline GAF & & $-.14 * *$ & & $-.13^{*}$ & & $-.36 * * *$ \\
\hline Step 2 & $.03 * * *$ & & .00 & & $.08 * * *$ & \\
\hline Age & & -.02 & & -.07 & & -.06 \\
\hline Gender & & .07 & & .01 & & .04 \\
\hline African American & & -.06 & & -.04 & & -.10 \\
\hline White/non-Hispanic & & -.11 & & .12 & & -.01 \\
\hline Income & & $-.10 *$ & & -.05 & & -.01 \\
\hline Major depressive disorder & & -.01 & & -.02 & & -.01 \\
\hline PTSD & & -.02 & & -.05 & & -.01 \\
\hline Schizophrenia & & -.07 & & .01 & & .04 \\
\hline Substance use disorder & & .08 & & .08 & & .02 \\
\hline GAF & & $-.14 * *$ & & $-.13^{*}$ & & $-.36 * * *$ \\
\hline Housing status & & $.20 * * *$ & & .05 & & $.31 * * *$ \\
\hline Total $R^{2}$ & $.12 * * *$ & & $.06^{*}$ & & $.25 * * *$ & \\
\hline$N$ & 380 & & 380 & & 379 & \\
\hline
\end{tabular}

\section{Hypothesis Two}

Hypothesis 2: There is an association between patient housing status and patient utilization of community resources (i.e. jail, psychiatric hospitalizations, and SAGE 
service hours). The results of the hierarchical multiple regression analyses support the hypothesis that there is an association between patient housing status and community resource utilization for incarceration and SAGE clinical service hours but not for psychiatric hospitalization. Patients who experienced homeless episodes had significantly more days in jail and hours of outpatient mental health service than other patients in the study.

\section{Research Question Three}

Question 3: Among community mental health patients, which patient characteristics (i.e. housing status, age, gender, race, income, DSM-IV-TR Axis I disorders(s) and DSM-IV-TR GAF score) are associated with service retention? Logistic regression was performed to assess the relationship between patient characteristics and patient service retention in the SAGE program during a 3-year period. The model contained 11 independent variables (housing status, age, gender, race, income amount, major depressive disorder, posttraumatic stress disorder, schizophrenia, substance use disorder, GAF, and months of enrollment). The full model containing all predictors was statistically significant, $X^{2}(14, N=380)=29.64, p=.009$, indicating that the model was able to distinguish between patients who retained services and those that did not. The model as a whole explained between $7.5 \%$ (Cox and Snell R square) and 10.7\% (Nagelkerke R squared) of the variance in service retention, and correctly classified $72.4 \%$ of the cases. As shown in Table 10, only two of the independent variables made a unique statistically significant contribution to the model (African America race and schizophrenia). The strongest predictor of service retention was schizophrenia, with an 
odds ratio of 3.05. This indicated that patients diagnosed with schizophrenia were more than 3 times as likely to have retained SAGE services compared with patients not diagnosed with schizophrenia, controlling for all other factors in the model. The odds ratio of .55 for the African American race variable was less than 1, indicating that African American patients were less likely to retain services compared to White/nonHispanic patients, controlling for other factors in the model. For additional detail on the results of this analysis see Table 10. 
Running head: RISK FACTORS FOR HOMELESSNESS AMONG MENTAL HEALTH PATIENTS

Table 10

Logistic Regression Predicting Likelihood of Patients Retaining SAGE Services

\begin{tabular}{|c|c|c|c|c|c|c|c|c|}
\hline \multirow[t]{2}{*}{ Predictor } & \multirow[t]{2}{*}{$B$} & \multirow[t]{2}{*}{ S.E. } & \multirow[t]{2}{*}{ Wald } & \multirow[t]{2}{*}{$d f$} & \multirow[t]{2}{*}{$p$} & \multirow[t]{2}{*}{$\begin{array}{l}\text { Odds } \\
\text { Ratio }\end{array}$} & \multicolumn{2}{|c|}{$\begin{array}{c}95.0 \% \text { CI for } \\
\text { Odds Ratio }\end{array}$} \\
\hline & & & & & & & Lower & Upper \\
\hline \multicolumn{9}{|l|}{ Housing status } \\
\hline Episodes of homelessness & 0.02 & 0.26 & 0.09 & 1 & .926 & 1.03 & 0.61 & 1.72 \\
\hline No homeless episodes & & & & & & 1.00 & & \\
\hline Age & 0.01 & 0.01 & 0.14 & 1 & .710 & 1.01 & 0.98 & 1.03 \\
\hline \multicolumn{9}{|l|}{ Gender } \\
\hline Male & -0.07 & 0.27 & 0.07 & 1 & .797 & 0.93 & 0.56 & 1.57 \\
\hline Female & & & & & & 1.00 & & \\
\hline \multicolumn{9}{|l|}{ Race } \\
\hline African American & -0.60 & 0.28 & 4.50 & 1 & .034 & 0.55 & 0.32 & 0.96 \\
\hline American Indian & 0.94 & 0.78 & 1.42 & 1 & .233 & 2.55 & 0.55 & 11.87 \\
\hline Latino/Hispanic & 0.13 & 0.46 & 0.09 & 1 & .769 & 1.14 & 0.47 & 2.80 \\
\hline Other race & -0.46 & 0.50 & 0.85 & 1 & .357 & 0.63 & 0.24 & 1.69 \\
\hline White/non-Hispanic & & & & & & 1.00 & & \\
\hline \multicolumn{9}{|l|}{ Income } \\
\hline Less than $\$ 700$ & 0.32 & 0.34 & 0.89 & 1 & .345 & 1.38 & 0.71 & 2.70 \\
\hline$\$ 700$ or more & & & & & & 1.00 & & \\
\hline \multicolumn{9}{|l|}{ Major depressive disorder } \\
\hline Yes & 0.19 & 0.27 & 0.49 & 1 & .483 & 1.21 & 0.71 & 2.06 \\
\hline No & & & & & & 1.00 & & \\
\hline \multicolumn{9}{|l|}{ PTSD } \\
\hline Yes & -0.02 & 0.32 & 0.00 & 1 & .963 & 0.99 & 0.53 & 1.84 \\
\hline No & & & & & & 1.00 & & \\
\hline \multicolumn{9}{|l|}{ Schizophrenia } \\
\hline Yes & 1.12 & 0.34 & 10.81 & 1 & .001 & 3.05 & 1.57 & 5.94 \\
\hline No & & & & & & 1.00 & & \\
\hline \multicolumn{9}{|l|}{ Substance use disorder } \\
\hline Yes & -0.15 & 0.26 & 0.33 & 1 & .564 & 0.86 & 0.52 & 1.42 \\
\hline No & & & & & & 1.00 & & \\
\hline GAF & -0.01 & 0.02 & 0.15 & 1 & .698 & 0.99 & 0.96 & 1.03 \\
\hline Months of enrollment & 0.01 & 0.01 & 2.17 & 1 & .141 & 1.01 & 1.00 & 1.02 \\
\hline
\end{tabular}


In addition to logistic regression analysis, chi-square and independent samples ttests were conducted to further evaluate whether differences existed between patients in the study cohort who had continuous enrollment in SAGE outpatient mental health services for the entire three years of the study compared with those who did not. The results of these tests indicate that the two groups are not distinguishable with the exception of the retained services group having more patients diagnosed with schizophrenia, fewer African Americans, and more patients whose overall length of time enrolled in mental health services was longer. Patient characteristics that did not differ significantly between patients who retained services and those who did not included the following: housing status, gender, race/ethnicity of American Indians, Hispanics, and Whites, income, major depressive disorder, PTSD, substance use disorder, age, and GAF scores. These results are consistent with the results of the logistic regression analysis with the exception of total months of enrollment in services. For additional detail on the results of this analysis see Table 11 and 12. 
Table 11

Chi-Square Tests to Evaluate Whether Characteristics of Patients Who Retained Services Differed From Patients Who Did Not Retain Services

\begin{tabular}{|c|c|c|c|c|c|c|}
\hline \multirow[b]{2}{*}{ Characteristic } & \multicolumn{2}{|c|}{ Retained services } & \multirow[b]{2}{*}{$\chi^{2}$} & \multirow[b]{2}{*}{$d f$} & \multirow[b]{2}{*}{$p$} & \multirow[b]{2}{*}{ Phi } \\
\hline & $\begin{array}{c}\text { Yes } \\
(\mathrm{N}=271) \\
\%\end{array}$ & $\begin{array}{c}\text { No } \\
(\mathrm{N}=109) \\
\%\end{array}$ & & & & \\
\hline Housing status & & & 1.92 & 1 & .166 & -.07 \\
\hline Episodes of homelessness & 67.8 & 32.2 & & & & \\
\hline No homeless episodes & 74.3 & 25.7 & & & & \\
\hline Gender & & & 0.47 & 1 & .491 & -.03 \\
\hline Male & 70.2 & 29.8 & & & & \\
\hline Female & 73.6 & 26.4 & & & & \\
\hline African American & & & 5.25 & 1 & .022 & -.19 \\
\hline Yes & 62.1 & 37.9 & & & & \\
\hline No & 74.4 & 25.6 & & & & \\
\hline American Indian & & & 2.85 & 1 & .091 & .09 \\
\hline Yes & 88.9 & 11.1 & & & & \\
\hline No & 70.4 & 29.6 & & & & \\
\hline Latino/Hispanic & & & 0.35 & 1 & .555 & .03 \\
\hline Yes & 75.8 & 24.2 & & & & \\
\hline No & 70.9 & 29.1 & & & & \\
\hline White/non-Hispanic & & & 1.94 & 1 & .164 & .07 \\
\hline Yes & 74.2 & 25.8 & & & & \\
\hline No & 67.7 & 32.3 & & & & \\
\hline Income & & & 0.38 & 1 & .535 & -.03 \\
\hline Less than $\$ 700$ & 71.9 & 28.1 & & & & \\
\hline$\$ 700$ or more & 67.9 & 32.1 & & & & \\
\hline Major depressive disorder & & & 0.19 & 1 & .664 & -.02 \\
\hline Yes & 69.7 & 30.3 & & & & \\
\hline No & 72.0 & 28.0 & & & & \\
\hline PTSD & & & 0.68 & 1 & .408 & -.04 \\
\hline Yes & 67.2 & 32.8 & & & & \\
\hline No & 72.2 & 27.8 & & & & \\
\hline Schizophrenia & & & 13.77 & 1 & $<.001$ & .19 \\
\hline Yes & 85.4 & 14.6 & & & & \\
\hline No & 66.1 & 33.9 & & & & \\
\hline Substance use disorder & & & 2.57 & 1 & .109 & -.08 \\
\hline Yes & 67.8 & 32.2 & & & & \\
\hline No & 75.3 & 24.7 & & & & \\
\hline
\end{tabular}


Table 12

Independent Samples T-Tests to Evaluate Whether Characteristics of Patients Who Retained Services Differed From Patients Who Did Not Retain Services

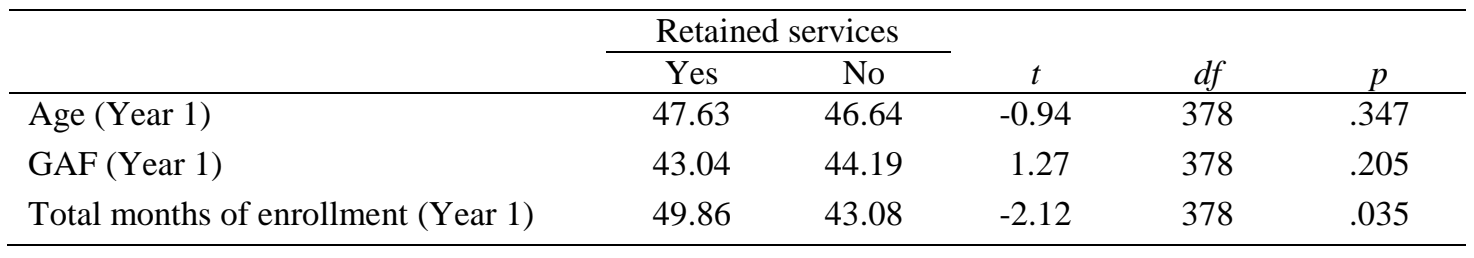

\section{Hypothesis Three}

Hypothesis 3: There is an association between patient characteristics (i.e. housing status, age, gender, race, income, DSM-IV-TR Axis I disorders[s] and DSM-IVTR GAF score) and service retention. The results of the logistic regression analysis support the hypothesis that there is an association between patient characteristics and service retention for two of the independent variables (i.e. African American race and schizophrenia). There was insufficient evidence to support this hypothesis for the other patient characteristics variables included in the model.

\section{Research Question Four}

Question 4: Is length of enrollment in community mental health services associated with patient outcomes for the following: days in jail, days in psychiatric hospital, SAGE service hours, DSM-IV-TR GAF scores, and housing status? This final research question was answered using two-way repeated measures ANOVA and Cochran's Q test. Four separate two-way repeated measures ANOVA tests were conducted, one for each quantitative outcome variable (i.e. number of days in jail, number of days of psychiatric hospitalization, SAGE service hours, and DSM-IV-TR 
GAF scores), to evaluate the effect of race, substance use, and homelessness on patient outcomes over a 3-year period.

The results of the first ANOVA indicated that the main effect for the composite variable race, substance use disorder, and homelessness on the outcome variable number of days in jail was significant, $F(1,269)=47.64, p<.001$, partial eta squared $=.15$, and the main effect for service year was significant, Wilks' Lambda $=.92, F(2,268)=10.82$, $p<.001$, partial eta squared $=.07$. The interaction effect between service year and the race, substance use disorder, and homelessness variable was also significant, Wilks’ Lambda $=.94, F(2,268)=8.73, p<.001$, partial eta squared $=.06$. The means and standard deviations for this ANOVA are presented in Table 13.

Table 13

Descriptive Statistics for Number of Days in Jail by Service Year and African American Race, Substance Use Disorder, and One or More Episodes of Homelessness

\begin{tabular}{lrrrrrrr}
\hline & \multicolumn{8}{c}{ Number of days in jail per year } \\
\cline { 2 - 8 } & & \multicolumn{3}{c}{2005} & \multicolumn{2}{c}{2006} & \multicolumn{2}{c}{2007} \\
\cline { 3 - 8 } $\begin{array}{l}\text { African American race, substance } \\
\text { use disorder, and homelessness }\end{array}$ & $\mathrm{n}$ & $\mathrm{M}$ & $\mathrm{SD}$ & $\mathrm{M}$ & $\mathrm{SD}$ & $\mathrm{M}$ & $\mathrm{SD}$ \\
\hline Yes & 26 & 30.58 & 49.90 & 12.85 & 22.01 & 13.00 & 28.63 \\
No & 245 & 2.98 & 12.04 & 2.80 & 15.75 & 1.64 & 6.66 \\
Total & 271 & 5.63 & 20.68 & 3.76 & 16.67 & 2.73 & 11.28 \\
\hline
\end{tabular}

The results of the second ANOVA indicated that the main effect for the composite variable race, substance use disorder, and homelessness on the outcome variable number of days of psychiatric hospitalization was nonsignificant, $F(1,269)=$ $.39, p<.531$, partial eta squared $=.00$, and the main effect for service year was nonsignificant, Wilks' Lambda $=1.00, F(2,268)=.28, p=.758$, partial eta squared $=$ 
.00 . The interaction effect between service year and the race, substance use disorder, and homelessness variable was also nonsignificant, Wilks' Lambda $=1.00, F(2,268)=.02, p$ $=.977$, partial eta squared $=.00$. The means and standard deviations for this ANOVA are presented in Table 14.

\section{Table 14}

Descriptive Statistics for Number of Days of Psychiatric Hospitalization by Service Year and African American Race, Substance Use Disorder, and One or More Episodes of Homelessness

\begin{tabular}{|c|c|c|c|c|c|c|c|}
\hline \multirow[b]{3}{*}{$\begin{array}{l}\text { African American race, substance } \\
\text { use disorder, and homelessness }\end{array}$} & \multicolumn{7}{|c|}{ Number of days of psychiatric hospitalization } \\
\hline & \multirow[b]{2}{*}{$\mathrm{n}$} & \multicolumn{2}{|c|}{2005} & \multicolumn{2}{|c|}{2006} & \multicolumn{2}{|c|}{2007} \\
\hline & & $\mathrm{M}$ & SD & $\mathrm{M}$ & $\mathrm{SD}$ & $\mathrm{M}$ & $\mathrm{SD}$ \\
\hline Yes & 26 & .12 & .59 & 1.00 & 2.99 & .19 & .98 \\
\hline No & 245 & 1.02 & 6.14 & 1.50 & 10.30 & 1.04 & 6.36 \\
\hline Total & 271 & .94 & 5.84 & 1.45 & 9.83 & .96 & 6.06 \\
\hline
\end{tabular}

The results of the third ANOVA indicated that the main effect for the composite variable race, substance use disorder, and homelessness on the outcome variable number of hours of SAGE services was nonsignificant, $F(1,267)=1.39, p=.240$, partial eta squared $=.00$. However, the main effect for service year was significant, Wilks' Lambda $=.96, F(2,266)=4.82, p=.009$, partial eta squared $=.03$, and the interaction effect between service year and the race, substance use disorder, and homelessness variable was also significant, Wilks' Lambda $=.98, F(2,266)=3.21, p=.042$, partial eta squared $=$ .02. The means and standard deviations for this ANOVA are presented in Table 15 . 
Table 15

Descriptive Statistics for Number of SAGE Service Hours by Service Year and African American Race, Substance Use Disorder, and One or More Episodes of Homelessness

\begin{tabular}{lrrrrrrr}
\hline & \multicolumn{6}{c}{ Number of hours of SAGE services per year } \\
\cline { 2 - 8 } & & \multicolumn{2}{c}{2005} & \multicolumn{3}{c}{2006} & \multicolumn{2}{c}{2007} \\
\cline { 2 - 8 } $\begin{array}{l}\text { African American race, substance } \\
\text { use disorder, and homelessness }\end{array}$ & $\mathrm{n}$ & $\mathrm{M}$ & $\mathrm{SD}$ & $\mathrm{M}$ & $\mathrm{SD}$ & $\mathrm{M}$ & $\mathrm{SD}$ \\
\hline Yes & 26 & 50.90 & 54.25 & 58.52 & 46.25 & 41.75 & 45.23 \\
No & 243 & 47.83 & 63.65 & 38.66 & 45.06 & 34.70 & 45.94 \\
Total & 269 & 48.13 & 62.72 & 40.58 & 45.47 & 35.38 & 45.84 \\
\hline
\end{tabular}

The results of the final ANOVA indicated that the main effect for the composite variable race, substance use disorder, and homelessness on Global Assessment of Functioning scores was nonsignificant, $F(1,269)=2.55, p=.111$, partial eta squared $=$ .01 , and the main effect for service year was nonsignificant, Wilks' Lambda $=1.00, F(2$, $268)=.19, p=.826$, partial eta squared $=.00$. The interaction effect between service year and the race, substance use disorder, and homelessness variable was also nonsignificant, Wilks' Lambda $=1.00, F(2,268)=.30, p=.737$, partial eta squared $=$ .00. The means and standard deviations for this ANOVA are presented in Table 16 .

Table 16

Descriptive Statistics for GAF Scores by Service Year and African American Race, Substance Use Disorder, and One or More Episodes of Homelessness

\begin{tabular}{lccccccc}
\hline & \multicolumn{6}{c}{ Global Assessment of Functioning scores } \\
\cline { 2 - 8 } & & \multicolumn{2}{c}{2005} & \multicolumn{2}{c}{2006} & \multicolumn{2}{c}{2007} \\
\cline { 2 - 8 } $\begin{array}{l}\text { African American race, substance } \\
\text { use disorder, and homelessness }\end{array}$ & $\mathrm{n}$ & $\mathrm{M}$ & $\mathrm{SD}$ & $\mathrm{M}$ & $\mathrm{SD}$ & $\mathrm{M}$ & $\mathrm{SD}$ \\
\hline Yes & 26 & 40.54 & 7.24 & 40.69 & 7.85 & 40.96 & 7.64 \\
No & 245 & 43.30 & 8.36 & 43.47 & 8.23 & 43.37 & 8.32 \\
Total & 271 & 43.04 & 8.29 & 43.21 & 8.22 & 43.14 & 8.27 \\
\hline
\end{tabular}


Nine separate Cochran's Q tests were conducted to evaluate whether the proportion of SAGE patients who experienced homelessness changed significantly over a 3-year period for patients overall and for patients belonging to each of the major demographic and diagnostic groups identified in this study. The results of the first Cochran's Q test, which included all SAGE patients who had continuous enrollment from 2005 to 2007 , was significant, $Q(2)=47.60, p<.001$, indicating that the proportion of SAGE patients overall who experienced homelessness decreased significantly during this period. All eight of the remaining Cochran's Q tests conducted, one for each the major demographic and diagnostic groups, were also significant (see Table 17). These results indicated that homelessness experienced by patients decreased across all major groups identified in this study regardless of gender, race, or diagnosis.

\section{Table 17}

Cochran's Q Test to Evaluate Whether the Proportion of SAGE Patients Experiencing Homelessness Changed Over a 3-Year Period of Continuous Enrollment in the SAGE Program

\begin{tabular}{|c|c|c|c|c|c|c|c|c|c|}
\hline \multirow[b]{2}{*}{ Variable } & \multirow[b]{2}{*}{$\mathrm{n}$} & \multicolumn{2}{|c|}{2005} & \multicolumn{2}{|c|}{2006} & \multicolumn{2}{|c|}{2007} & \multicolumn{2}{|c|}{ Cochran's Q } \\
\hline & & $\mathrm{M}$ & SD & $\mathrm{M}$ & SD & $\mathrm{M}$ & SD & $X^{2}$ & $p$ \\
\hline \multicolumn{10}{|l|}{ Overall } \\
\hline All SAGE patients & 271 & .39 & .49 & .27 & .44 & .21 & .41 & 47.60 & $<.001$ \\
\hline \multicolumn{10}{|l|}{ Gender } \\
\hline Male & 179 & .39 & .49 & .25 & .43 & .21 & .41 & 36.13 & $<.001$ \\
\hline Female & 92 & .39 & .49 & .30 & .46 & .22 & .41 & 13.24 & .001 \\
\hline \multicolumn{10}{|l|}{ Race } \\
\hline White/non-Hispanic & 158 & .32 & .47 & .22 & .41 & .14 & .35 & 30.33 & $<.001$ \\
\hline African American & 59 & .58 & .50 & .39 & .49 & .39 & .49 & 11.00 & .004 \\
\hline \multicolumn{10}{|l|}{ Axis I disorder } \\
\hline Major depression & 76 & .38 & .49 & .29 & .46 & .24 & .43 & 8.45 & .015 \\
\hline PTSD & 45 & .40 & .49 & .24 & .43 & .20 & .40 & 9.57 & .008 \\
\hline Schizophrenia & 88 & .33 & .47 & .16 & .37 & .14 & .34 & 22.52 & $<.001$ \\
\hline $\begin{array}{l}\text { Substance use } \\
\text { disorder }\end{array}$ & 137 & .50 & .50 & .36 & .48 & .31 & .47 & 20.79 & $<.001$ \\
\hline
\end{tabular}




\section{Hypothesis Four}

Hypothesis 4: Patient outcomes (i.e. days in jail, days in psychiatric hospital, SAGE service hours, DSM-IV-TR GAF scores, and housing status) differ based on how long a patient has been enrolled in services. The results of the ANOVA and Cochran's Q tests support the hypothesis that patient outcomes differ based on length of enrollment in services for the outcome variables days in jail, SAGE service hours, and housing status. Length of time enrolled in outpatient mental health services was associated with fewer days in jail, fewer hours of SAGE services, and decreased homelessness.

However, there was insufficient evidence to support the hypothesis that psychiatric hospitalization and GAF outcomes differed based on patients' length of enrollment.

\section{Summary}

In this chapter, descriptive statistics were presented followed by the results of bivariate and multivariate analysis used to answer the four research questions and hypotheses of this study. The results of the logistic regression used for the first research question and hypothesis, revealed that the association between patient characteristics and homelessness were significant for age, race, income amount, and substance use disorder. Patients who were younger, African American, had incomes of less than $\$ 700$, or were diagnosed with a substance use disorder were more likely to have experienced homelessness than other patients in the study.

The results of the hierarchical multiple regression analyses used for the second research question and hypothesis provided evidence of an association between patient housing status and community resource utilization for jail and SAGE outpatient mental 
health services but not for inpatient psychiatric hospital services. Patients who were homeless tended to have more days in jail and more hours of outpatient mental services than other patients in the study.

The results of the logistic regression analysis used to answer the third research question and hypothesis indicated that the association between patient characteristics and service retention was significant for two of the independent variables, race and schizophrenia. African American patients were less likely to retain services compared with non-Hispanic Whites. Patients diagnosed with schizophrenia were more likely to retain services compared to patients with other mental health disorders.

The results of the ANOVA and Cochran's Q tests indicated that patient outcomes differed significantly based on time enrolled in services for the outcome variables days in jail, SAGE service hours, and housing status. As patients' length of time enrolled in outpatient mental health services increased, days in jail and SAGE service hours decreased, and patients were less likely to experience homelessness. However, psychiatric hospitalization and GAF outcomes did not appear to be influenced by length of enrollment. The next chapter will include a discussion of the findings, implications for practice, and recommendations for further research. 


\section{CHAPTER V}

\section{SUMMARY, DISCUSSION, AND CONCLUSIONS}

\section{Introduction}

In the preceding chapter, the presentation and analysis of data have been reported. Chapter Five consists of a summary of the study, discussion of the findings, implications for practice and policy, recommendations for further research, limitations, and conclusions.

\section{Summary of the Study}

This study focused on answering research questions related to the social problem of homelessness among persons with SMI. Homelessness for this subset of the homeless population results in a diminished quality of life for both homeless and non-homeless members of communities where homelessness exists. The purpose of the study was to identify risk factors associated with homelessness within this patient population, to assess the relationship between housing status and consumption of costly publicly funded resources, to identify characteristics associated with service retention, and to evaluate whether length of treatment for these individuals is associated with better patient outcomes.

The public health model was the organizing theoretical framework of the study. Health promotion and harm reduction are the major components of this model relevant to the dissertation. Consistent with the basic principles of health promotion and harm 
reduction, the study sought to identify relationships between key variables that could contribute to pragmatic solutions to promote health and reduce harm to individuals and society.

The study consisted of a review of the records of 380 patients who had continuous enrollment in community mental health services in 2005 at an agency that specializes in working with homeless and formerly homeless adults. The records of the 312 patients from this cohort who had continuous enrollment in 2006 and the 271 patients who had continuous enrollment in 2007 were also reviewed. Descriptive statistics for demographic and clinical characteristics were provided for the following variables: gender, age, ethnicity, income amount, income source, housing status, mental health disorders, substance use disorders, GAF scores, total months enrolled in this community mental health program, number of days in jail, number of days in psychiatric hospital, and number of hours of community mental health services received during each year of the study. The study included four research question and hypothesis pairs.

Question 1: Among community mental health patients, which patient characteristics (i.e. age, gender, race, income, DSM-IV-TR Axis I disorder[s], and DSMIV-TR GAF score) are associated with episodes of homelessness when comparing patients who experienced homelessness with those who did not?

Hypothesis 1: There is an association between patient characteristics (i.e. age, gender, race, income DSM-IV-TR Axis I disorder[s], and DSM-IV-TR GAF score) and housing status. 
Question 2: Do community mental health patients who experience episodes of homelessness consume more community resources (i.e. jail, psychiatric hospitalizations, and SAGE service hours) than patients who do not experience homelessness?

Hypothesis 2: There is an association between patient housing status and patient utilization of community resources (i.e. jail, psychiatric hospitalizations, and SAGE service hours).

Question 3: Among community mental health patients, which patient characteristics (i.e. housing status, age, gender, race, income, DSM-IV-TR Axis I disorders(s) and DSM-IV-TR GAF score) are associated with service retention?

Hypothesis 3: There is an association between patient characteristics (i.e. housing status, age, gender, race, income, DSM-IV-TR Axis I disorders[s] and DSM-IVTR GAF score) and service retention.

Question 4: Is length of enrollment in community mental health services associated with patient outcomes for the following: days in jail, days in psychiatric hospital, SAGE service hours, DSM-IV-TR GAF scores, and housing status?

Hypothesis 4: Patient outcomes (i.e. days in jail, days in psychiatric hospital, SAGE service hours, DSM-IV-TR GAF scores, and housing status) differ based on how long a patient has been enrolled in services.

For the first research question and hypothesis, logistic regression was used to examine the relationship between patient characteristics and housing status. Hierarchical 
multiple regression was used for the second research question and hypothesis to assess the relationship between housing status and patient utilization of community resources. Logistic regression was used again for the third research question and hypothesis, this time to assess the relationship between patient characteristics and retention of outpatient mental health services. For the final research question and hypothesis, the relationship between length of time in mental health services and patient outcomes was evaluated using two-way repeated measures ANOVA and Cochran's Q tests.

\section{Discussion of the Findings}

In this section, the findings for each of the four research questions and four hypotheses are discussed. The results are explained and compared with previous research findings. Possible explanations for these why these results may have occurred are also discussed.

\section{Research Question One and Hypothesis One}

Question 1: Among community mental health patients, which patient characteristics (i.e. age, gender, race, income, DSM-IV-TR Axis I disorder[s], and DSMIV-TR GAF score) are associated with episodes of homelessness when comparing patients who experienced homelessness with those who did not? Hypothesis 1: There is an association between patient characteristics (i.e. age, gender, race, income, DSM-IVTR Axis I disorder[s], and DSM-IV-TR GAF score) and housing status.

The findings from the first research question and hypothesis indicate that African American race, substance use, lower income, and younger age are associated with 
increased risk for homelessness among SAGE patients in the study cohort. Patient characteristics not found to be associated with increased or decreased risk for homelessness included Hispanic and American Indian race/ethnicity, gender, major depression, PTSD, schizophrenia, and GAF scores.

Race and homelessness. African Americans were found to be overrepresented among SAGE patients and overrepresented among SAGE patients who experienced homelessness. African Americans made up $25 \%$ of the study cohort, while only making up $8 \%$ of the general population in Seattle (U.S. Census Bureau, 2010). During the 3 year period from 2005 to 2007, 65\% of African American patients experienced homelessness compared to $39 \%$ for Whites. The finding that there is an overrepresentation of African Americans among persons experiencing homelessness is consistent with other research on homelessness (Folsom et al., 2005; HUD, 2010; Koegel et al., 1995; Rossi, 1989; U.S. Conference of Mayors, 2007). Among these other studies, the Folsom et al. (2005) study is the most similar to this one in that it also involved a review of community mental health records. However, it should be noted that the racial/ethnic makeup San Diego County, California, where the Folsom et al. study was conducted, differs from Seattle. While the percentage of Whites, African Americans, Asians, and American Indians is similar, Hispanics represent about $7 \%$ of the Seattle population compared to $32 \%$ in San Diego County (U.S. Census Bureau, 2010).

Possible explanations for why African Americans in the study cohort were disproportionately homeless may include discrimination in housing and healthcare and fewer community resources. Although racial discrimination may be less overt than it was 
prior to the passage of the Civil Rights Act of 1964 and the Fair Housing Act of 1968, it continues to exist. The concept of structural racism helps to explain how widespread racism could persist in a post-civil rights society decades after laws were enacted that make racial discrimination illegal. The Aspen Roundtable on Community Change (2004) describes structural racism as, "a system in which public policies, institutional practices, cultural representations, and other norms work in various, often reinforcing ways to perpetuate racial group inequity." According to this concept, an individual's position on the privilege scale is determined by race, with people the upper end of the scale (typically Whites) having better access to opportunity and power and people at the lower end (typically persons of color) experiencing economic disadvantage and political isolation (p. 11).

The concept of intersectionality as used by Frank Cooper (2006) provides another explanation of how this type of discrimination can occur. Whites often fear Black males of a certain type, he contends. This type is what he calls the "Bad Black Man" who is crime prone. The "Good Black Man," on the other hand is more assimilated into mainstream society and has middle class values. Intersectionality comes into play when an individual occupies more than one marginalized category, for example, homeless and Black or mental illness plus Black. The prejudice against him or her is then compounded.

Pager (2003) and Pager, Western, and Bonikowski (2009) test the concept of intersectionality in their research on the low-wage labor market. Their research provides evidence that the effect of race can be magnified by additional factors such as criminal 
history. These researchers found that employers were more likely to make job offers to Whites with criminal records than to African Americans with clean records. African Americans with criminal records were least likely to receive a job offer. It is conceivable that something similar happens within the housing application process. For example, housing providers may be more willing to take a chance on renting to a White applicant with a history of criminal activity or substance use than to an African American applicant with a comparable history.

Interestingly, homelessness among American Indian and Hispanic patients was not found to differ significantly compared to White patients. This result differs from Folsom et al. (2005) who found that Hispanics were less likely than Whites to experience homelessness. Folsom et al. did not report on American Indian risk for homelessness.

The documentation of the disproportionate numbers of African Americans with SMI experiencing homelessness that has emerged in this study provides additional evidence of possible discrimination on the basis of race. The relationship between race and homelessness is complex and further research is needed to assess to what extent racial discrimination influences decisions on who receives housing and gets to keep it.

Substance use and homelessness. SAGE patients with co-occurring mental health and substance use disorders were significantly more likely to have experienced homelessness than were SAGE patients without a co-occurring substance use disorder. This finding is consistent with previous research (Olfson, Mechanic, Hansell, Boyer, \& Walkup, 1999; Caton et al., 2005; Folsom et al., 2005; Shelton, Taylor, Bonner, \& van 
den Bree, 2009). Slightly more than half (53\%) of SAGE patients in the study cohort were diagnosed with a substance use disorder in addition to a mental health disorder. Among patients diagnosed with co-occurring disorders, 66\% experienced one or more episodes of homelessness during a 3 year period compared to $35 \%$ for patients without a substance use disorder.

A substance use disorder could contribute to homelessness in a variety of ways. Someone with housing could become homeless by spending money on alcohol or other drugs instead of on rent or having frequent visitors coming and going using and buying drugs in one's apartment, either of which could lead to eviction and then homelessness. For someone who is already homeless, substance dependence or abuse could make it harder to exit homelessness for a number of reasons including spending future rent and deposit money on alcohol or other drugs, not being able to pass a background check due to drug convictions, or being too intoxicated or high to follow through with the application process. While this study and previous studies provide evidence that there is a relationship between substance use disorders and homelessness, future studies need to examine how substance use disorders influence homelessness for individuals with SMI.

Income and homelessness. Patients with monthly incomes of less than $\$ 700$ were more likely to experience homelessness than patients with incomes of $\$ 700$ or higher. Olfson et al. (1999), Caton et el. (2005), Folsom et al. (2005), and Shelton et al. (2009) did not report on the effect of income amount on homelessness, therefore it is not possible to compare this finding with previous research. However, it does make sense that having less money would equate to a diminished ability to afford housing. Finding 
affordable housing can be difficult for people with low incomes, especially in Seattle where the average rent for a one-bedroom in 2007 was $\$ 839$ (Housing Development Consortium, 2007). At this same time, Washington's general assistance cash benefits (GA-U and GA-X) were only \$339 a month and SSI was \$623. SAGE patients with significant work histories received SSDI in varying amounts based on earned work credits ranging from $\$ 328$ to $\$ 1505$ per month. With affordable housing generally considered to cost no more than $30 \%$ of a person's income (HUD, 2011) even the higher income SAGE patients would have difficulty affording market-rate housing. In Seattle and other high rent cities, homeless individuals receiving state or federal disability income often can only afford housing if they are able to get a housing voucher or an apartment in a subsidized housing project. Unfortunately, subsidized housing waitlists tend to be long and it can take several years for an applicant to reach the top of the list. Future research should examine the relationship between income and homelessness closer to assess whether this relationship is as straightforward as it appears or if other factors such as work histories, which could indicate later onset of more severe mental health symptoms, play a role.

Age and homelessness. Younger patients were more likely to experience homelessness than older patients. The mean age of patients who had episodes of homelessness was 46 and for those who did not experience homelessness the mean age was 50. This finding differs from Folsom et al. (2005), whose study did not find an association between younger age and homelessness. However, this finding is consistent 
with the findings of an earlier study of the general adult homeless population by Koegel, Melamid, and Burnam (1995).

It is not known why younger patients in this study were more likely to experience homelessness. One possible explanation could be that the process of obtaining housing could take several years making those with housing older than patients without housing. Homeless housing programs might also be more likely to accept older applicants believing them to be less likely to have behavioral issues. Future studies are needed to examine the relationship between younger age and homelessness in other community mental health samples as well as what factors may contribute to this difference.

Gender and homelessness. Previous studies have found men to be overrepresented among adults in the general homeless population (Koegel et al., 1995) and men more at risk for homelessness among community mental health patients (Folsom et al., 2005). Unlike previous studies, this study did not find evidence of a relationship between gender and homelessness. The percentage of men and women who experienced homelessness during the 3 year study period was very similar, $45 \%$ for men and $47 \%$ for women. This finding provides evidence that the likelihood of continued or repeated episodes of homelessness among community mental health patients with histories of homelessness may not differ between men and women. Approximately $99 \%$ of patients in the SAGE cohort had histories of homelessness prior to the start of the study. Koegel et al. and Folsom et al. did not report the percentage of participants in their studies who had histories of homelessness. Further research is needed to examine risk for homelessness among men and women with and without histories of homelessness. 
Running head: RISK FACTORS FOR HOMELESSNESS AMONG MENTAL HEALTH PATIENTS

Mental health disorders, GAF, and homelessness. The likelihood of experiencing homelessness did not differ significantly between patients with a diagnosis of or without a diagnosis of major depression, PTSD, or schizophrenia. These results are consistent with Herman, Susser, Jandorf, Lavelle, and Bromet (1998) who also found that risk for homelessness did not differ significantly among mental health diagnostic groups. Based on their findings, Herman et al. speculated that more general factors related to severe mental illness, such as lower income and limited family support, may influence homelessness risk more so than disorder-specific manifestations. Unlike this study, Folsom et al. (2005) found that patients with schizophrenia and bipolar disorder had higher rates of homelessness compared to patients with depression. Future research should assess diagnosis specific risk for homelessness in other populations including the general population. Future research should also investigate whether there are specific factors associated with severe mental illness that contribute to increased risk for homelessness that individuals with different disorders have in common.

Patient GAF scores were also not found to be associated with increased or decreased homelessness. This was an unexpected finding and differs from Folsom et al. (2005) who found that patients with lower GAF scores (more severe symptoms) had higher rates of homelessness. It makes sense that patients with more severe mental health symptoms would be more at risk for homelessness and it is not known why this study did not find evidence of this. It is conceivable that this result is due to other factors unique to the SAGE cohort such as the SAGE mental health program being part of a homeless services agency that may be better equipped to assist patients with more severe symptoms 
obtain and maintain housing who might otherwise be more at risk for homelessness if served elsewhere. This agency, the Downtown Emergency Service Center, owns and operates supportive housing projects that provide housing to many of the SAGE patients. Further research is needed to evaluate whether lower GAF scores are associated with increased homelessness in other community mental health samples including programs with and without access to supportive housing.

\section{Research Question Two and Hypothesis Two}

Question 2: Do community mental health patients who experience episodes of homelessness consume more community resources (i.e. jail, psychiatric hospitalizations, and SAGE service hours) than patients who do not experience homelessness? Hypothesis 2: There is an association between patient housing status and patient utilization of community resources (i.e. jail, psychiatric hospitalizations, and SAGE service hours).

The findings from the second research question and hypothesis indicate that patients who experienced homelessness tended to have more days in jail and more hours of outpatient mental services than other patients in the study. Homelessness was not found to be associated with an increase or decrease in utilization of inpatient psychiatric services.

Incarceration and homelessness. Patients who had one or more episodes of homelessness during the 3 year study period had significantly more days in jail than patients who did not experience homelessness. Patients who experienced homelessness had a mean of 11.9 days of jail per year compared with 1.5 for patients who did not 
experience homelessness. This finding is consistent with previous research on homelessness and incarceration (Culhane, Metraux, \& Hadley, 2001; Fitzpatrick \& Myrstol, 2011; Greenberg \& Rosenheck, 2008).

Homeless individuals are likely at increased risk for incarceration for a number of reasons. These reasons could include crimes of survival, such as stealing food, trespassing on private property to avoid victimization, or breaking into an unoccupied building to escape bad weather (Snow, Baker, \& Anderson, 1989). Homeless people may also be more visible to law enforcement than other people and when doing something illegal may be more likely to be observed. Homeless individuals are also more vulnerable to being arrested for activities that would be legal if they occurred in the privacy of a home but could be illegal when done in public such as loitering, public urination or public intoxication. It has also been suggested that homeless individuals, viewed by the mainstream as having unconventional behavior and appearance, are arrested and placed in jail to remove and discourage these individuals from having a presence in certain locations in the community (Fitzpatrick \& Myrstol, 2011).

Income amount and GAF scores were also found to be associated with incarceration. Patients with lower monthly incomes tended to have more days of incarceration than patients with higher incomes. Patients who were incarcerated had mean monthly incomes of $\$ 562$ compared with $\$ 620$ for patients who were not incarcerated. Although the difference between these means is only $\$ 58$, the finding that lower income is associated with increased incarceration is consistent with previous research on poverty and the criminal justice system (Reiman \& Leighton, 2010; Western 
\& Pettit, 2010). Individuals with limited financial resources are clearly at a disadvantage when involved in the legal system. They are less able to pay fines, court fees, bail, or hire experienced defense attorneys.

Patients with lower GAF scores also tended to have more days in jail than patients with higher GAF scores. The mean GAF score for patients who were incarcerated was 42 compared to 44 for patients who were not incarcerated. Though clinically this difference is small, it makes sense that patients whose GAF scores indicate lower psychiatric functioning would be more at risk for incarceration. This result is consistent with prior research (Kravitz, Cavanaugh, \& Rigsbee, 2002; Prince, Akincigil, \& Bromet, 2007).

Community mental health service hours and homelessness. Patients who experienced homelessness during the 3 year study period had significantly more hours of mental health services than patients who did not experience homelessness. Patients with one or more episodes of homelessness had a mean of 52.4 service hours per year compared with 27.3 for patients who did not experience homelessness during this same period. This finding suggests that homeless patients served by the SAGE mental health program required considerably more agency resources than patients with stable housing. Mental health services for the vast majority of SAGE patients are paid for with Medicaid dollars administered by the county using a managed care model. Therefore, because SAGE receives a set case rate per Medicaid patient per month, this agency receives no additional compensation for extra staff time spent assisting homeless patients. 
Community mental health patients who are homeless may require additional hours of agency staff time compared with non-homeless patients for a number of reasons including extra time needed for outreach and engagement, accommodating unscheduled appointments, and assisting with the provision of basic needs (i.e. food, clothing, and shelter). If indeed homeless patients are more costly for agencies to serve, this uncompensated extra cost would be a disincentive that would likely result in a reluctance of some community mental health agencies to do the outreach and engagement necessary to enroll these patients and keep them connected with services.

In contrast to this study, Folsom et al. (2005), found that homeless patients utilized outpatient mental services less than patients with housing. Folsom et al. studied community mental patients enrolled in multiple agencies across San Diego County, California. These different results could possibly be explained by a difference in the effort made by these agencies to serve homeless patients. An agency that uses a more traditional approach to working with patients, with most services provided by phone or during scheduled office appointments, could actually spend less time assisting homeless patients than non-homeless patients because services conducted in this manner are less accessible to homeless patients.

Lower GAF scores were also found to be associated with increased service hours. This was not an unexpected finding as it makes sense that patients with GAF scores indicating lower functioning would utilize more service hours than patients with GAF scores that indicate higher functioning. Patients with lower psychiatric functioning often require a lot more direct hands-on assistance from mental health agency staff than higher 
functioning patients. For example, lower functioning patients may require more frequent appointments with psychiatrics, nursing staff, and mental health case managers for treating and monitoring psychiatric symptoms. These patients may also require more assistance with money management, medication monitoring, scheduling and attending medical appointments, shopping for essentials, or arranging chore worker services to clean their apartments.

The results of this study indicate that SAGE patients who experienced homelessness tended to require significantly more staff service hours than patients who did not experience homelessness. The only prior study found in the literature that examined homelessness and utilization of outpatient mental health services had the opposite finding (Folsom et al., 2005). Further research is needed to assess the effect of homelessness on the need for increased service hours from community mental health staff. This is important to study because not only is this potentially an additional poorly tracked cost of homelessness, but also because when agencies lack the flexibility to accommodate homeless patients' need for additional service hours and assistance with activities traditional mental health agencies are less accustom to providing, these patients will likely end up being served elsewhere in the community at a greater cost (e.g. hospital emergency departments, jail, etc.).

Additional studies are also needed that assess the relationship between GAF scores and patients' need for increased service hours at other community mental health agencies, perhaps comparing more traditional agencies with agencies that have more flexibility in how they serve patients. Related to this, future research also needs to be 
conducted with the aim of identifying the specific types of assistance mental health patients with lower GAF scores need to live successfully in the community.

Utilization of inpatient psychiatric services and homelessness. Homelessness was not found to be associated with an increase or decrease in utilization of inpatient psychiatric services. This finding differs from Culhane, Metraux, and Hadley (2001) and Folsom et al. (2005), who both found that homeless participants in their studies utilized inpatient psychiatric services more than non-homeless participants. This non-significant finding may have occurred due to the relatively small number of patients in the sample who had psychiatric hospitalizations. Only 40 patients out of 380 (less than $11 \%$ ) had psychiatric hospitalizations during the 3 year study period. However, approximately $73 \%$ of these patients experienced homelessness during this same period.

The only variable in the model that was significantly associated with inpatient psychiatric services was patient GAF scores. Patients with lower GAF scores, indicating lower psychiatric functioning, had more days of psychiatric hospitalization than patients with higher GAF scores. Patients with one or more psychiatric hospitalizations had a mean GAF score of 40 compared to 44 for patients not hospitalized during the study period. This was an expected finding and is consistent with prior research on GAF and psychiatric hospitalization (Mulder, Koopmans, \& Lyons, 2005). It is fairly well accepted that individuals experiencing more severe psychiatric symptoms (e.g. psychosis, mania, or severe depression or anxiety) are more likely to require inpatient hospitalization than patients with less severe symptoms (Camacho, Ng, Bejarano, Simmons, \& Chavira, 2010; Lyons et al., 1997). 


\section{Research Question Three and Hypothesis Three}

Question 3: Among community mental health patients, which patient characteristics (i.e. housing status, age, gender, race, income, DSM-IV-TR Axis I disorders(s) and DSM-IV-TR GAF score) are associated with service retention? Hypothesis 3: There is an association between patient characteristics (i.e. housing status, age, gender, race, income, DSM-IV-TR Axis I disorders[s] and DSM-IV-TR GAF score) and service retention.

The findings from the third research question and hypothesis indicate that, among patients in the SAGE study cohort, a diagnosis of schizophrenia was associated with an increased likelihood of retaining community mental health services and African American race was found to be associated with increased likelihood of not retaining services. Patient characteristics not found to be associated with increased or decreased likelihood of retaining mental health services included housing status, age, gender, Hispanic and American Indian race/ethnicity, income, major depression, PTSD, GAF scores, substance use disorders, and months of enrollment.

Mental health disorders, GAF, and service retention. Patients diagnosed with schizophrenia were found to be significantly more likely to retain mental health services compared to patients not diagnosed with schizophrenia. The service retention rate for patients with schizophrenia was $85 \%$ over a 3 year period. Patients who were not diagnosed with schizophrenia had a service retention rate of $66 \%$. This finding is consistent with prior research (Berghofer, Schmidl, Rudas, Steiner, \& Schmitz 2002; 
Rossi et al., 2002; Ruggeri et al., 2007). This might seem surprising given that symptoms of schizophrenia can include paranoia or disorganization (American Psychiatric Association, 2000). However, perhaps this higher retention rate to some extent results from patients with schizophrenia often having few other places in the community where their participation is actively encouraged and efforts are made to make these individuals feel accepted.

Service retention rates for patients with and without major depression and PTSD did not differ significantly. Previous research on the effect of major depression, PTSD, and other mental health disorders on service retention have been mixed. Consistent with this study, Rossi et al. (2002) also did not find an association between major depression (and other mood disorders) and PTSD (and other anxiety disorders) and service retention or dropout. However, Wang (2007) found that mood disorders were associated with dropping out of services and Baruch, Vrouva, and Fearon (2009) found that patients diagnosed with anxiety or depression were more likely to retain services than other patients.

There was also no evidence of a relationship between GAF scores and service retention. This finding is consistent with prior research by Rossi et al. (2002). This finding suggests that patients' level of psychological, social, and occupational functioning did not significantly influence service retention.

It is apparent from these mixed results in the literature, some consistent with and some that differ from the results of this study, that further research is needed to assess 
whether specific mental health disorders are associated with service retention or dropout. Future research should be conducted across multiple community mental health settings and should include independent variables on patients' stated reasons for seeking services. It is likely that patients seek out community mental health services for different specific reasons. If patients feel they are receiving adequate assistance with their primary issues or concerns, it makes sense that these patients would be more likely to continue with services whereas patients who feel their needs are not being adequately addressed would be more likely to drop out.

Race and service retention. African American patients were found to have a significantly lower service retention rate than Whites. Over the course of the 3 year study period, $62 \%$ of African American patients retained mental health services with the SAGE program compared with $74 \%$ of Whites. Service retention rates for Hispanic and American Indian patients did not differ significantly from Whites.

The finding that African Americans have lower service retention rates than Whites is consistent with prior research (Kazdin, Stolar, \& Marciano, 1995; Wang, 2007; Wierzbicki \& Pekarik, 1993). Other related research has found that among individuals diagnosed with a mental health disorder, African Americans were less likely than Whites to access or receive mental health services (Alegria et al., 2008; Keyes, 2008; Snowden, 1999).

It is unknown why significantly more African American SAGE patients left services compared to Whites. There are likely multiple factors that contribute to this 
difference. Researchers have previously suggested that African Americans are less likely than Whites to connect with or continue in mental health services for reasons that include inadequate attention to ethnic and cultural differences (Thompson, Neighbors, Munday, \& Jackson, 1996), stigma of mental illness (Alvidrez, Snowden, \& Kaiser, 2008), and distrust of physicians (Armstrong, Ravenell, McMurphy, \& Putt, 2007). Further research is needed to better understand why service retention rates are lower for African Americans than for Whites. Once these reasons are better understood, it may be possible to design better strategies to keep African Americans engaged in mental health services.

Housing status and service retention. The service retention rates of patients who experienced homelessness did not differ significantly from patients who did not experience homelessness. This result differs from prior research by Baruch et al. (2009) who found that homeless patients were more likely to drop out of mental health services and Folsom et al. (2005) who found that homelessness was associated with decreased outpatient utilization and increased inpatient utilization. Perhaps because the SAGE mental health program is part of a homeless services agency, they are better able to keep homeless patients engaged in services, which may explain why service retention rates are similar for homeless and non-homeless SAGE patients. Future studies should compare service retention rates of homeless and non-homeless patients served by homeless service agencies compared with more traditional community mental health agencies.

Income and service retention. Service retention rates for patients with monthly incomes of less than $\$ 700$ did not differ significantly from patients with incomes of $\$ 700$ or higher. This finding is consistent with prior research on income and mental health 
service retention (Edlund et al., 2002; Wang, 2007). While income amount may influence other factors, based on the findings of this study and others, it does not appear to have an effect on service retention. In most cases, patients in this study had their services fully covered by Medicaid, therefore affordability of services based on income and other expenses was not a determining factor for remaining in services for most SAGE patients. Future research should assess whether service retention rates differ between patients with lower and higher incomes when cost of services is a factor such as when patients do not have insurance and need to pay privately for services or have insurance but have to pay insurance copayments.

Gender and service retention. Service retention rates for men and women did not differ significantly. Previous research on gender and mental health service retention have had mixed results. Consistent with this study, Edlund et al. (2002), Wang (2007), and Olfson et al. (2009) also found no association between gender and service retention. However, Nosé, Barbui and Tansella (2003) found that men were more likely to drop out of services than women. Further research is needed to assess whether retention rates differ between men and women in other community mental health samples.

Age and service retention. Patient age was not significantly associated with retaining services. Prior research on age and service retention has had mixed results. This finding is consistent with Olfson et al. (2009). However, it differs from Nosé et al. (2003), Wang (2007), and O’Brien, Fahmy, and Singh (2009) who found that younger patients had a higher rate of leaving mental health services prematurely. Wang (2007) found that patients $15-25$ years old were more likely to drop out than patients in age 
categories older than this. O'Brien et al. (2009) suggest that younger patients may have less insight and more difficulty accepting diagnosis of an illness. If indeed younger mental health patients are more at risk for dropping out of services, this may not have been detectable within the SAGE study cohort due to the limited number of young adults and no adolescents within this sample. The youngest patient in the SAGE study cohort was 22 years old and only 17 patients (less than 5\%) were 30 or younger. Further research is needed to assess whether age is associated with service retention or dropout in other community mental health samples.

Substance use and service retention. A diagnosis of a substance use disorder was not found to be associated with service retention. This finding was unexpected and differs from prior research on mental health service retention. Researchers have previously found that patients who have co-occurring substance use disorders have a higher rate of leaving mental health services prematurely (Nosé, Barbui \& Tansella, 2003; Wang, 2007) and that patients with co-occurring disorders are more difficult to engage (O'Brien et al., 2009). The SAGE program's use of the harm reduction approach, motivational interviewing, and close collaboration with on-site chemical dependency program staff may have contributed to this finding. Further research is needed to identify specific reasons why patients with co-occurring disorders retain services or drop out. Future research should compare patient retention across multiple community mental health agencies with similar patient populations and with different treatment approaches or different levels of mental health and chemical dependency service integration. 
Months of enrollment and service retention. Based on the results of the logistic regression analysis, service retention rates did not differ significantly based on the number of months patients were enrolled in SAGE services. This finding differs from Rossi et al. (2002) who found that the more time a patient was enrolled in mental health services the more likely it was that he or she would continue services. Other related research has indicated that dropout is most likely to occur within the first two counseling sessions (Olfson et al., 2009). Patients in the SAGE study cohort had continuous periods of enrollment ranging from 12 months to nine years. Therefore, early dropout could not be assessed within this sample. The finding from this study provides evidence that for patients with 12 or more months of enrollment, length of enrollment is not a significance factor for predicting service retention. Future research should compare service retention rates of community mental health patients from date of initial referral for services to multiple years of enrollment to gain a better understanding of whether patients' risk for dropout is greater at any point during the enrollment and post-enrollment periods.

\section{Research Question Four and Hypothesis Four}

Question 4: Is length of enrollment in community mental health services associated with patient outcomes for the following: days in jail, days in psychiatric hospital, SAGE service hours, DSM-IV-TR GAF scores, and housing status? Hypothesis 4: Patient outcomes (i.e. days in jail, days in psychiatric hospital, SAGE service hours, DSM-IV-TR GAF scores, and housing status) differ based on how long a patient has been enrolled in services. 
The findings from the fourth research question and hypothesis indicate that patient outcomes for incarceration, outpatient mental health service hours, and homelessness improved over time for patients in the study cohort during the 3 year study period. From the first year to the third year patients on average had fewer days in jail, fewer hours of outpatient mental health services, and decreased homelessness. However, during this same time period, outcomes for psychiatric hospitalization and GAF did not change significantly.

Incarceration over time. Patients' mean number of days in jail per year decreased significantly over time. The mean number of annual days in jail dropped by about half from Year 1 to Year 3 of the study suggesting that one of the long-term benefits of ongoing participation in community mental health services is reduced involvement in the criminal justice system. A review of the literature found that the relationship between outpatient mental health services and incarceration has received very limited research attention. Several researchers who studied incarceration of persons with SMI recommended increasing efforts to link currently incarcerated inmates who have mental health disorders with community mental health services at time of release to reduce jail recidivism (Baillargeon, Binswanger, Penn, Williams, \& Murray, 2009; Buck, Brown, \& Hickey, 2011; Wilper et al., 2009). However, only one previous study was identified that examined the effects of ongoing community-based mental health services on reducing incarceration. In that study, Gilbert et al. (2010) found that individuals with SMI who were court ordered to participate in outpatient mental health services had significantly fewer arrests while enrolled in mental health services than they did prior to 
enrollment. Unlike this study, Gilbert et al. found no significant change in incarceration rates over time among study participants who were voluntarily receiving services.

A possible explanation for the decrease in incarceration rates is that patients over time, with the support of ongoing outpatient mental health treatment, do better in multiple ways that work together to reduce the likelihood of involvement in the criminal justice system. For example, after a year of outreach and engagement from a mental health case manager, a male homeless patient with SMI and co-occurring substance dependence might agree to meeting with the staff psychiatrist to start psychiatric medications that reduce the patient's depressive and psychotic symptoms. The patient begins to feel less hopeless about his situation and agrees to fill out some housing applications. He also starts attending chemical dependency groups. During Year 2, he is accepted into a supportive housing project and with ongoing encouragement from his mental health case manager, continues taking psychiatric medications and attending chemical dependency groups. By Year 3, this patient is psychiatrically stable, has stable housing, and decreased substance use. The combination of these or possibly any one of these could lead to decreased incarceration. Further research is needed to better understand the effects of long-term community mental health on jail recidivism for homeless and formerly homeless individuals with SMI.

Outpatient mental health service use over time. The mean number of outpatient mental health service hours for patients in the study cohort decreased by approximately $26 \%$ over the 3 year study period. A review of the literature revealed no similar studies making a direct comparison with previous research not possible. The 
research that does appear in literature tends to focus on interventions designed to increase outpatient utilization as a strategy to decrease use of more costly inpatient or residential mental health services (Gilmer, Stefancic, Ettner, Manning, \& Tsemberis, 2010; Shirk, 2008; Shumway, Boccellari, O’Brien, \& Okin, 2008). While heavy outpatient service use may be overlooked by researchers and policymakers, it is an issue that potentially has a negative impact on homeless persons with SMI. This is because these individuals likely require more service hours than other patients and in states that deliver Medicaid funded community mental health services through HMO style managed Medicaid mental health networks, there is an obvious disincentive to serve patients needing more service hours. The reason for this is that mental health agencies that are part of a managed Medicaid provider network receive a fixed monthly rate for each enrolled patient rather than fee-for-service payments (Shirk, 2008).

The results of this study suggest that one of the long-term effects of ongoing enrollment in community mental health services for patients in the study cohort was that they required fewer hours of mental health services over time. Though the specific reasons for this association are not known, a likely explanation is that patients with continuous enrollment in outpatient services improve over time, gradually needing less support from agency staff to function successfully in the community. Patients likely need more staff time early on for outreach, psychiatric stabilization, and housing assistance (if homeless or new to housing). Future research should examine whether patients with SMI served by other community mental health agencies need more staff time closer to time of intake and gradually less over time. 
Homelessness over time. During the 3 year study period, homelessness decreased significantly among patients in the SAGE study cohort. From Year 1 to Year 3, the percentage of patients who experienced homelessness dropped by about half. The findings also indicated that the decrease in homelessness was significant across all major groups identified in this study including men, women, Whites, and African Americans as well as patients diagnosed with major depression, PTSD, schizophrenia, and substance use disorders.

A direct comparison with previous research was not possible as no comparable research was found in a review of the literature. The long-term effect of community mental health services on homelessness appears to have only received limited attention. Prior research on interventions to reduce homelessness among persons with SMI has tended to focus on specialized mental health programs, such as assertive community treatment (Coldwell \& Bender, 2007), or specialized housing, such as housing first programs (Pearson, Montgomery, \& Locke, 2009).

The finding that homelessness decreased significantly over time for the patients in the study cohort regardless of gender, race, mental health diagnosis, or use of substances provides evidence that ongoing community mental health services can be effective at reducing homelessness for mental health patients with a diversity of demographic and clinical characteristics. The decrease in homelessness over time was likely due to a variety of reasons. Some possible explanations include patients' gradual increased trust of service providers resulting in a willingness to accept housing and patients' names finally reaching the top of long housing waitlists. 
Future research should assess whether homelessness decreases over time for patients enrolled in other community mental health programs. Rates of homelessness for individuals with SMI enrolled in services and not enrolled in services should also be compared over a period of several years.

Psychiatric hospitalization over time. Patients' mean number of annual days of inpatient psychiatric hospitalization did not change significantly from Year 1 to Year 3. This may in part be because patients' mean number of days of psychiatric hospitalization was fairly low to begin with, at approximately one day per year during Year 1. Furthermore, only a small number of patients were hospitalized during the 3 year study period (less than 11\%). The low mean number of hospitalization days and the relatively low percentage of patients hospitalized during the study period suggest that patients in the study cohort as a whole were not an especially high utilizing group of patients. The findings of this study related to psychiatric hospitalization and outpatient mental health therefore cannot be easily compared with previous research. Prior studies that reported an association between outpatient mental health services and reduced inpatient hospitalization, including studies by Shumway et al. (2008) and Swartz et al. (2010), typically utilized study samples with high rates of pre-intervention hospitalization. Additional research on the effect of outpatient mental health treatment on inpatient psychiatric hospital utilization over time with homeless and formerly homeless adults with SMI is needed. Future studies should include a patient sample with a large proportion of patients with recent hospitalizations. 
GAF scores over time. Despite improved outcomes in several other areas, patients' mean annual GAF scores did not change significantly during the 3 year study period. Similar to this finding, Moos, Nichol, and Moos (2002) found that patients in their study who achieved major improvements in social and occupational functioning, as indicated by other measures, had GAF scores that indicated only minimal improvement. However, in at least two other studies in the literature GAF was found to be correlated with other outcome measures that assess social and occupational functioning (Schwartz, 2007; Startup, Jackson, \& Bendix, 2002). It is unknown why patients in the study cohort had GAF scores that, on average, remained relatively unchanged across the 3 year study period. This result is somewhat surprising, given that other outcome measures showed improvement including housing and incarceration. One possible explanation could be that clinical staff failed to update GAF scores when patients had improved social, occupational, and psychological functioning. Another possible explanation could be that patients' overall functioning did not improve, but rather changes occurred in their environment that resulted in improvements in other outcomes that would normally be thought of as indicators of improved individual functioning. To illustrate this latter explanation, imagine that a homeless woman with schizoaffective disorder has her name added to a housing waitlist by her mental health case manager. Later on this individual is selected to receive an apartment at a supportive housing project and moves in with encouragement from her case manager. She now has housing and is not being arrested as frequently because the crimes she was previously arrested for where mostly crimes that people without housing are charged with such as trespassing and urinating in public. 
However, she continues to have suicidal ideation, is unable to obtain a job, and is unable to establish social relationships. Therefore even though two indicators (housing status and incarceration) would suggest improved overall functioning, her actual functioning is unchanged and it would be appropriate for her GAF to remain the same as when she was homeless.

Future research should examine more closely whether GAF is a useful outcome measure or if it is more of a descriptive characteristic when used with patients with severe chronic mental health disorders.

\section{Implications for Practice and Policy}

This research has provided me with an opportunity to explore in some depth the phenomenon of homelessness among persons with severe mental health disorders. It has also allowed me the chance to explore the influence of demographic and clinical characteristics on housing stability and service retention, the influence of housing stability on community resource utilization, and the effect of length of enrollment on patient outcomes. Only with the knowledge that comes from this and other studies can informed public policy decisions be made that will, in a meaningful manner, lead to pragmatic policies to help end current homelessness and prevent future homelessness for individuals with SMI.

The findings from this dissertation have substantial public health implications. The finding concerning the much higher rate of incarceration for mental health patients who were without stable housing provides empirical support for the importance of 
providing housing for people who are homeless, regardless of whether they are using illicit drugs, drinking heavily, or refusing psychiatric medications. The cost savings to the community from reduced incarceration rates and decreased mental health service hours could be enormous.

From a public health standpoint, homelessness is closely correlated with poor health and a shortened life expectancy. The focus of a public health model is on prevention. The extent of the crisis of homelessness in the United States makes prevention an urgent priority of government officials and other policymakers. Apicello (2010) emphatically argues for the necessity of addressing both macro- and micro-level risk factors for homelessness at three levels — individual, institutional, and societal. As he states:

A concerted effort is needed to prevent homelessness before it occurs by addressing root causes in the general social environment. Additionally, preventing homelessness among identified high-risk groups, such as persons with mental health, substance abuse or trauma histories, require targeted interventions that go beyond what is done to improve the social environment for the general population. Addressing these multiple levels from a prevention-oriented approach, rather than a crisis management and rehabilitative treatment approach, requires a comprehensive conceptualization of prevention that addresses the fundamental contextual and individual causes of homelessness. 
Apicello discusses homeless prevention in terms of primary prevention (e.g. keeping homelessness from occurring in the first place by increasing the availability of affordable housing), secondary prevention (e.g. helping newly homeless individuals get back into housing), and tertiary prevention which focuses on lessening the negative effects of homelessness for individuals who have been homeless for a significant amount time (i.e. chronic homelessness). It is this latter form of homelessness and prevention that I have studied in this dissertation with the hope that what is learned from this study can contribute to improved primary and secondary homeless prevention strategies. In any case, the offering of direct intervention to persons most at risk of becoming or staying homeless is of vital importance in ending homelessness at the individual level.

As part of a prevention strategy to reduce the physical, psychological, and economic harm that individuals and communities suffer as a result of homelessness, the federal government needs to invest more money for subsidized housing vouchers and supportive housing projects. An increased supply of affordable housing would result in shorter waitlists and hopefully less time that individuals with SMI would spend homeless. Supportive housing can be an essential ingredient for successful housing for individuals who need on ongoing support from on-site staff. This type of housing can also provide greater access to mental health, chemical dependency, and medical services. For individuals needing less staff support, a housing voucher could make housing success possible just by making it economically feasible to rent an apartment on state or federal disability income. 
The system of managed care, as indicated in my analysis, fails to provide financial incentives to encourage community mental health agencies to serve homeless patients and to assist them with obtaining and maintaining housing. Such incentives are needed to encourage agencies to spend extra time with patients who need more staff time due to being homeless or at risk for becoming homeless. Perhaps states should consider paying mental health agencies higher Medicaid reimbursement rates when they enroll patients who are homeless to encourage agencies to do more outreach and to make more of an effort to try to keep patients enrolled and engaged in services. Financial incentives should also be considered for serving patients considered to be at greater risk for homelessness including patients with co-occurring mental health and chemical dependency disorders.

Policy makers and social workers need to give heed to the finding in this dissertation of disproportionately high rates of homelessness among African American mental health patients. Further research is needed to understand why this is the case and to work to remove the barriers African Americans with SMI face in receiving the help they need to acquire and maintain stable housing. Cultural competency should be evaluated and additional training provided at multiple levels from non-profit mental health and housing providers to government social service agencies. Policies should also be reviewed and revised as needed to ensure that these policies are promoting agencies and their staff to provide services in a culturally competent manner.

Low income and an insufficient supply of affordable housing are other factors that likely contribute to decreased housing stability for African Americans with SMI. 
Supplemental Security Income (SSI) payments for which persons with SMI qualify are too low to allow individuals who receive this money to find affordable housing in the cities unless they are lucky enough to get a housing subsidy. A substantial increase in SSI payments and an increase in the availability of subsidized housing could help reduce the rate of homelessness among all individuals with SMI. Increased SSI payments and more subsidized housing would also hopefully reduce the effect of racial discrimination on housing by giving individuals more housing options.

At the macro level, we would do well to recognize that people with disabilities have the right to housing and other services so they can achieve their full potential and function in the community to the level to which they are capable. According to Article 25 of the United Nations Universal Declaration of Human Rights (1948), “everyone has the right to a standard of living adequate for health...including food, clothing, housing and medical care and necessary social services in the event of unemployment, sickness, disability... in circumstances beyond his control."

\section{Recommendations for Further Research}

In agreement with the recommendations of Apicello (2010), in his analysis of the research needs according to a public health risk model, I recommend that future research:

- Evaluate programs across sites to compare programs that use different models as well as those that may have similar approaches but implement interventions differently; 
- Use longitudinal designs for long-term analyses;

- Employ multilevel studies that investigate risk factors at both the population and individual levels.

More specifically, as a result of my research findings I call for the need for further research on the influence of race/ethnicity, substance use, income, and age on the likelihood that someone with SMI will experience homelessness. Knowledge of why certain individuals are more at risk for homelessness than others is essential for improving old interventions and designing new interventions to end homelessness and prevent future homelessness. Concerning race/ethnicity, future research should examine why African Americans with SMI appear to be more at risk for homelessness than nonAfrican Americans. For example, is learned helplessness, intergenerational poverty, discrimination, a combination of these or other factors that cause African Americans to be more at risk for homelessness? Regarding substance use, future studies could compare housing retention rates of individuals with co-occurring disorders provided with housing at housing projects that are accepting of residents who use substances (both illicit and non-illicit) and tolerate their use and compare this with housing retention rates of individuals with co-occurring disorders placed in more traditional subsidized housing projects. Future research on the effect of income on homelessness could assess whether homeless individuals with SMI who are provided with enough income to afford moderately priced efficiency or studios apartments would do with obtaining and maintaining housing compared to homeless individuals receiving standard cash benefit amounts. Future research on age and homelessness should be focused on identifying 
factors that make individuals in different age groups more or less at risk for homelessness. For example, are housing providers more likely to rent to older adults because they are perceived as more vulnerable and less likely to damage property than younger adults and are younger adults less willing to accept housing that they feel would diminish their sense of autonomy?

Other future research should include evaluating whether providing additional financial incentives to community mental health agencies that enroll homeless individuals with SMI would result in increased outreach and engagement and decreased homelessness. Regarding service retention, future research should examine whether dropout is significantly higher for African American patients than for Whites at other community mental health agencies and if so additional research should be conducted to identify reasons for this difference.

\section{Limitations}

As with all studies, this study has several limitations. One key limitation of the study is that the findings are generalizable only to patients of the SAGE mental health program as these individuals are defined as the study's population. However, it is reasonable to infer that the homeless and formerly homeless patients served at this community mental health program are not too dissimilar from other homeless and formerly homeless persons with SMI served at other community mental health programs in large urban areas. 
Related to this, a further limitation was that the sample was drawn from a special focus agency. The SAGE mental health program specializes in serving homeless and formerly homeless adults with SMI. While the SAGE patients may be similar to homeless and formerly homeless patients at other agencies, it is likely this agency's approach to working with these patients would be different than agencies with less experience serving this subset of the community mental health patient population.

Another limitation is the study's reliance on agency records that were originally collected for purposes other than for research. The records may have contained data that were entered incorrectly or not updated frequently by agency staff. Possibly related to this, as was mentioned earlier in this chapter, patients in the study cohort had GAF scores that remained relatively unchanged across the 3 year study period, while at the same time other outcome measures showed improvement. One explanation for this could be that clinical staff failed to update GAF scores when patients had improved functioning. It is also possible that patients' actual GAF scores were not correlated with other outcomes. Potential problems caused by this limitation were hopefully minimized by quality controls that were in place to maintain data quality including internal and external audits. Clinical supervisors also regularly reviewed charts and monthly data reports.

Lastly, a larger sample size would have made more subgroup comparisons possible. The dataset contained some variables with many categories such as race/ethnicity, mental health disorder, and substance use disorder that would have allowed for additional subgroup comparisons if there had a sufficient number of participants in each of these categories. 


\section{Conclusions}

A major purpose of this study, as this chapter has stated, was to identify risk factors associated with homelessness within a population of community mental health patients diagnosed with SMI. Using a sample size of 380 patients drawn from case management records of the SAGE mental health program, a number of variables were examined to assess their relationship to homelessness including age, gender, race income, mental health disorders, substance use disorders, and GAF scores. Risk factors for homelessness identified in this study include being of African American race, having a co-occurring substance use disorder, having lower than $\$ 700$ of monthly income, and being younger in age. A disproportionately high number from this population who experienced homelessness were African American bears further study. The finding that substance use emerged as a risk factor for homeless provides some evidence of a need for a wider availability of chemical dependency treatment in the community and greater availability of supportive housing projects that do not require abstinence.

A second major area of investigation was to assess the relationship between housing status and consumption of costly publicly funded resources. A comparison of community mental health patients who experienced homelessness and those who did not showed major differences between the two groups. In fact, patients who were homeless had 8 times as many days of incarceration and required approximately twice as many hours of mental health staff time compared with patients in the same program who had stable housing during the same time period. These findings illustrate the importance of 
providing mental health services in conjunction with supportive housing for keeping people with SMI in housing and out of jail. These findings also provide evidence that significantly more staff time is required to work with homeless individuals with SMI. Policymakers need to recognize the extra cost associated with serving these patients and should consider providing financial compensation to make it economically feasible for community mental health agencies belonging to managed Medicaid networks to serve homeless patients. These agencies typically operate on shoestring budgets. Without funding to cover the cost of additional staff time, some agencies may avoid serving homeless patients and others will not be able to adequately meet their needs.

Concerning service retention, a significant finding was that patients with schizophrenia were more likely to retain enrollment in mental health services than patients who did not have this diagnosis. The only patient characteristic associated with decreased likelihood of retaining services was African American race. Other clinical and demographic characteristics were non-significant. Overall, service retention among patients in the SAGE program appeared to be fairly good. Of note, it is interesting that patients with co-occurring disorders and patients who experienced homelessness were not found to be more at risk for dropping out than other patients. The contrast between this finding and the findings of other research in the literature is striking. The ability to retain patients often considered high-risk clientele suggests that the SAGE program's use of the harm reduction model and motivational interviewing techniques have been used effectively by this program to keep most patients engaged in services. However, 
additional research is needed to identify strategies to improve service retention among African American patients.

Unique to this study is the examination of the long-term effects of outpatient mental health treatment on outcomes for homeless and formerly homeless individuals with SMI over a 3-year period. During this time there was a substantial decline in homelessness. This trend occurred for patients with all major demographic and clinical characteristics included in the analysis. Homelessness decreased significantly even for patient groups previously identified as being at increased risk for homelessness by this and prior research including African American patients and patients with substance use disorders. Overall incarceration rates and mental health service hours also decreased significantly over time. These findings provide strong evidence that long-term community-based mental health services can be effective at reducing homelessness and incarceration as well as lead to a reduced patient dependence on mental health program staff for successful community living. 


\section{References}

Alegria, M., Chatterji, P., Wells, K., Cao, Z., Chen, C., Takeuchi, D.,...Meng, X. (2008). Disparity in depression treatment among racial and ethnic minority populations in the United States. Psychiatric Services, 59(11), 1264-1272.

Allness, D., \& Knoedler, W. (2003). National program standards for ACT teams. Arlington, Virginia: National Alliance for the Mentally Ill.

Alvidrez, J., Snowden, L., \& Kaiser, D. (2008). The experience of stigma among Black mental health consumers. Journal of Health Care for the Poor and Underserved, 19(3), 874-893. doi: 10.1353/hpu.0.0058

American Psychiatric Association. (2000). Diagnostic and statistical manual of mental disorders (4th ed., Text Revision). Washington, DC: Author.

Apicello, J. (2010). A paradigm shift in housing and homeless services: Applying the population and high-risk framework to preventing homelessness. The Open Health Services and Policy Journal, 3, 41-52.

Armstrong, K., Ravenell, K., McMurphy, S., \& Putt, M. (2007). Racial/ethnic differences in physician distrust in the United States. American Journal of Public Health, 97(7), 1283-1289. doi:10.2105/AJPH.2005.080762

Aspen Roundtable of Community Change. (2004). Structural racism and community building. Washington, DC: Aspen Institute. 
Bahr, H. (1969). Family size as antecedents of homelessness and excessive drinking. Journal of Marriage and the Family, 66, 477-483.

Baillargeon, J., Binswanger, I., Penn, J., Williams, B., \& Murray, O. (2009). Psychiatric disorders and repeat incarcerations: The revolving prison door. American Journal of Psychiatry, 166(1), 103-109.

Ball, A. (2007). HIV, injecting drug use and harm reduction: A public health response. Addiction, 102(5), 684-690.

Barker, R. (Ed.). (2003). The social work dictionary ( $5^{\text {th }}$ ed). Washington, DC: NASW Press.

Baruch, G., Vrouva, I., \& Fearon, P. (2009). A follow-up study of characteristics of young people that dropout and continue psychotherapy: Service implications for a clinic in the community. Child and Adolescent Mental Health,14(2), 69-75. doi: 10.1111/j.1475-3588.2008.00492.x

Barusch, A. S. (2002). Foundations of social policy: social justice, public programs, and the social work profession. Itasca, Il: F.E. Peacock Publishers.

Bassuk, E., Bennett, K, Bernstein, T., Davis, L., Denton, A., Grandin, M., ... Zerger, S. (2010). Services in supportive housing: Annual report 2010. Rockville, MD: Center for Substance Abuse and Mental Health Services Administration. 
Running head: RISK FACTORS FOR HOMELESSNESS AMONG MENTAL HEALTH PATIENTS

Berghofer, G., Schmidl, F., Rudas, S., Steiner, E., \& Schmitz , M. (2002). Predictors of treatment discontinuity in outpatient mental health care. Social Psychiatry and Psychiatric Epidemiology, 37(6), 276-282.

Bogue, D. (1963). Skid row in American cities. Chicago: University of Chicago.

Brunette, M., Drake, R., Woods, M., \& Hartnett, T. (2001). A comparison of long-term and short-term residential treatment programs for dual diagnosis patients.

Psychiatric Services, 52(4), 526-528.

Buck, D., Brown, C., \& Hickey, J. (2011). The jail inreach project: Linking homeless inmates who have mental illness with community health services. Psychiatric Services, 62(2), 120-122.

Burt, M., Hedderson, J., Zweig, J., Ortiz, M., Aron-Turnham, L., \& Johnson, S. (2004). Strategies for reducing chronic street homelessness. Washington, DC: Urban Institute.

Burt, M., Aron, L., Douglas, T., Valente, J., Lee, E., \& Iwen, B. (1999). Homelessness: Programs and the people they serve-Summary report-Findings of the National Survey of Homeless Assistance Providers and Clients. Washington, DC: Urban Institute.

Burt, M., Aron, L., Lee, E., \& Valente, J. (2001). Helping America's homeless: Emergency shelter or affordable housing? Washington, DC: Urban Institute. 
Burt, M., Pollack, D., Sosland, A, Mikelson, K, Drapa, E., Greenwalt, K., et al. (2002). Evaluation of continuums of care for homeless people: Final report. Washington, DC: U.S. Department of Housing and Urban Development.

Camacho, A., Ng, B., Bejarano, A, Simmons, A., \& Chavira, D. (2010). Crisis visits and psychiatric hospitalizations among patients attending a community clinic in rural Southern California. Community Mental Health Journal. Advanced online publication. doi: 10.1007/s10597-010-9350-0

Caton, C., Dominguez, B., Schanzer, B., Hassin, D., Shrout, P., Felix, A., ...Hsu, E. (2005). Risk factors for long-term homelessness: Findings from a longitudinal study of first-time homeless single adults. American Journal of Public Health, 95(10),1753-1759. doi:10.2105/AJPH. 2005.063321

Civil Rights Act of 1964, 42 U.S.C. $§ 2000$ e et seq.

Cohen, M. (2001). Homeless people. In A. Gitterman, (Ed.), Hand book of social work practice with vulnerable and resilient populations, $2^{\text {nd }} E d$ (pp. 628-650). New York: Columbia University Press.

Coldwell, C., \& Bender, W. (2007). The effectiveness of assertive community treatment for homeless populations with severe mental illness: A meta-analysis. American Journal of Psychiatry, 164(3), 393-399.

Collins, S., Malone, D., Clifaselfi, S., Ginzler, J., Garner, M., Burlingham, B.,... Larimer, M. (2012). Project-based housing first for chronically homeless individuals with 
Running head: RISK FACTORS FOR HOMELESSNESS AMONG MENTAL HEALTH PATIENTS

alcohol problems: Within-subjects analyses of 2-year Alcohol trajectories. American Journal of Public Health, 102(3), 511-519. doi:

10.2105/AJPH.2011.300403

Conklin, T. (2004, October). A public health model care for corrections. Corrections Today, 66(6), 120-124.

Cooper, F. (2006). Against bipolar Black masculinity: Intersectionality, assimilation, identity performance, and hierarchy. Law Review, University of California, Davis, 39(3), 853-906.

Coughey, K., Feighan, K., Lavelle, K., Olson, K., DeCarlo, M., \& Medina, M. (1999). Project H.O.M.E.: A comprehensive program for homeless individuals with mental illness and substance use disorders. Alcoholism Treatment Quarterly, 17(1/2), 133-148.

Culhane, D., Metraux, S., \& Hadley, T. (2001). The Impact of Supportive Housing for Homeless People with Severe Mental Illness on the Utilization of the Public Health, Corrections and Emergency Shelter Systems. Washington, DC: Fannie Mae Foundation. Retrieved from http://www.campaign4housing.org/pdfs/Culhane_NY_NY.pdf

Davis, S. (2004). Designing for the homeless. Berkeley: University of California Press.

Department of Veterans Affairs. (2012). Homelessness among veterans. Retrieved from http://www1.va.gov/homeless/ 
Doyle, E., \& Ward, S. (2001). The process of community health education and promotion. Long Grove, IL: Waveland Press.

East Downtown Community Association v. Downtown Emergency Service Center, No. 52101-2-I (Washington Ct. App. July 7, 2003).

Edlund, M., Wang, P., Berglund, P., Katz, S., Lin, E., \& Kessler, R. (2002). Dropping out of mental health treatment: Patterns and predictors among epidemiological survey respondents in the United States and Ontario. American Journal of Psychiatry, $159(5), 845-851$.

Fair Housing Act of 1968, 42 U.S.C. $§ 3601$ et seq.

Fitzpatrick, K., \& Myrstol, B. (2011). The jailing of America’s homeless: Evaluating the rabble management thesis. Crime \& Delinquency, 57(2), 271-297. doi: 10.1177/ 0011128708322941

Folsom, D., Hawthorne, W., Lindamer, L., Gilmer, T., Bailey, A., \& Golshan, S. (2005). Prevalence and risk factors for homelessness and utilization of mental health services among 10,340 patients with serious mental illness in a large public mental health system. American Journal of Psychiatry, 162(2), 370-376.

Fraser, M. \& Richman, J. (1999). Risk, protection, and resilience: Toward a conceptual framework for social work practice. Social Work Research, 23(3), 131-144. 
Running head: RISK FACTORS FOR HOMELESSNESS AMONG MENTAL HEALTH PATIENTS

Frisman, L., Covell, N., \& Hoburg, R. (2004). Cost-effectiveness analysis. In D. Levinson (Ed.), Encyclopedia of homelessness (Vol. 1, pp. 86-91). Thousand Oaks, CA: Sage.

Gilbert, A., Moser, L., Van Dorn, R., Swanson, J., Wilder, C., Robbins, P., ...Swartz, M. (2010). Reductions in arrest under assisted outpatient treatment in New York. Psychiatric Services, 61(10), 996-999.

Gilmer, T., Stefancic, A., Ettner, S., Manning, W., \& Tsemberis, S. (2010). Effect of fullservice partnerships on homelessness, use and costs of mental health services, and quality of life among adults with serious mental illness. Archives of General Psychiatry, 67(6), 645-652.

Goldman, H. (1999). The obligation of mental health services to the least well off. Psychiatric Services, 50(5), 659-663.

Green, A., Drake, R., Brunette, M., \& Noordsy, D. (2007). Schizophrenia and cooccurring substance use disorder. American Journal of Psychiatry, 164(3), 402408.

Greenberg, G. \& Rosenheck, R. (2008). Jail incarceration, homelessness, and mental health: A national study. Psychiatric Services, 59(2), 170-177. doi: 10.1176/appi.ps.59.2.170 
Grob, G. (2000). Mental health policy in $20^{\text {th }}$-century America. In R. Manderscheid and M. Henderson, (Eds.), Mental health, United States, 2000 (pp. 3-14). Rockville, Maryland: Substance Abuse \& Mental Health Services Administration.

Herman, D., Susser, E., Jandorf, L., Lavelle, J., \& Bromet, E. (1998). Homelessness among individuals with psychotic disorders hospitalized for the first time: Findings from the Suffolk County Mental Health Project. American Journal of Psychiatry, 155(1), 109-113.

Hilsenroth, M., Ackerman, S., Blagys, M., Baumann, B., Baity, M., \& Smith, S. et al. (2000). Reliability and validity of DSM-IV-TR axis V. American Journal of Psychiatry, 157, 1858-1863.

Homeless Emergency Assistance and Rapid Transition to Housing Act of 2009, 42 U.S.C. $§ 11301$ et seq.

Hopper, K. (2003). Reckoning with homelessness. London: Cornell University Press.

Housing Development Consortium (2007). King County housing facts. Retrieved from http://www.housingconsortium.org/nonprofit/documents/KCFactSheet2007.pdf

James, D., \& Glaze, L. (2006). Bureau of Justice Statistics special report: Mental health problems of prison and jail inmates. Washington, DC: U.S. Department of Justice.

Jencks, C. (1994). The homeless. London: Harvard University Press.

Jenson, J. (2007). Research, advocacy, and social policy: Lessons for the risk and resilience model. Social Work Research, 31(1), 3-5. 
Running head: RISK FACTORS FOR HOMELESSNESS AMONG MENTAL HEALTH PATIENTS

Joint Committee on Health Education and Health Promotion Terminology (2001). Report of the 2000 Joint Committee on Health Education and Promotion Terminology. American Journal of Health Education, 32(2), 89-104.

Jones, C. (2007, June 13). Berkley council passes plan to stop bad street behavior. San Francisco Chronicle, p. B1.

Katz, M. (2001). The price of citizenship: Redefining the American welfare state. New York: Owl Books.

Kazdin, A., Stolar, M., \& Marciano, P. (1995). Risk factors for dropping out of treatment among White and Black families. Journal of Family Psychology, 9(4), 402-417.

Kelley, V. (1998). Mental health and social work. In H. Johnson, (Ed.), The social services: An introduction (pp. 157-177). Itasca, IL: F.E. Peacock Publishers.

Kessler, R., Chiu, W., Demler, O., \& Walters, E. (2005). Prevalence, severity, and comorbidity of 12-month DSM-IV-TR disorders in the national comorbidity survey replication. Archives of General Psychiatry, 62(6), 617-627.

Keyes, K., Hatzenbuehler, M., Alberti, P., Narrow, W., Grant, B., \& Hasin, D. (2008). Service utilization differences for Axis I psychiatric and substance use disorders between White and Black adults. Psychiatric Services, 59(8), 893-901.

Koegel, P., Melamid, E., \& Burnam, A. (1995). Childhood risk factors for homelessness among homeless adults. American Journal of Public Health, 85(12), 1642-1649. 
Kowal, J. (2006, July 5). Homeless alcoholics receive a permanent place to live, and drink. New York Times.

Kravitz, H., Cavanaugh, J., \& Rigsbee, S. (2002). A cross-sectional study of psychosocial and criminal factors associated with arrest in mentally ill female detainees. Journal of the American Academy of Psychiatry and the Law, 30, 380-390.

Lanterman-Petris-Short Act, Cal. Welf. \& Inst. Code $§ 5000$ (1967).

Larimer, M., Malone, D., Garner, M., Atkins, D., Burlingham, B., Lonczak, H.,... Marlatt, A. (2009). Health care and public service use and costs before and after provision of housing for chronically homeless persons with severe alcohol problems. Journal of the American Medical Association, 301(13), 1349-1357. doi: 10.1001/jama.2009.414

Lyons, J., O’Mahoney, M., Miller, S., Neme, J., Kabat, J., \& Miller, F. (1997). Predicting readmission to the psychiatric hospital in a managed care environment: Implications for quality indicators. American Journal of Psychiatry, 154(3), 337340.

Marlatt, A. (1996). Harm reduction: Come as you are. Addictive Behaviors, 21, 779-788.

Marlatt, A. (1998). Basic principles and strategies of harm reduction. In A. Marlatt (Ed.), Harm reduction: Pragmatic strategies for managing high-risk behaviors (pp. 4966). New York: Guildford. 
Running head: RISK FACTORS FOR HOMELESSNESS AMONG MENTAL HEALTH PATIENTS

Marrero, C., Robles, R., Colon, H., Reyes, J., Matos, T., Sahai, H., et al. (2005). Factors associated with drug treatment dropout among injection drug users in Puerto Rico. Addictive Behaviors, 30, 397-402.

McCoy, M., Robins, C., Bethel, J., Tornow, C., \& Frey, W. (2007). Evaluation of homeless outreach projects and evaluation: Final evaluation report. Rockville, Maryland: Westat. Retrieved from http://www.ssa.gov/homelessness/docs/hopefinalreport.doc

Mental Health Systems Act of 1980, 42 U.S.C. $§ 9401$ et seq. (West 1980).

Miller, W., \& Rollnick, S. (2002). Motivational interviewing: Preparing people for change. New York: Guildford Press.

Moore, T. (2006). Estimated cost savings following enrollment in the community engagement program: Findings from a pilot study of homeless dually diagnosed adults. Portland, Oregon: Central City Concern.

Moos, R., Nichol, A., \& Moos, B. (2002). Global Assessment of Functioning ratings and the allocation and outcomes of mental health services. Psychiatric Services, 53(6), $730-737$.

Morse, G. (2004). Case management. In D. Levinson, Encyclopedia of homelessness (pp. 46-49). Thousand Oaks, CA: SAGE.

Mueser, K., Noordsy, D., Drake R., \& Fox, M. (2003): Integrated treatment for dual disorders: A guide to effective practice. New York: Guilford. 
Running head: RISK FACTORS FOR HOMELESSNESS AMONG MENTAL HEALTH PATIENTS

Mulder, C., Koopmans, G., \& Lyons, J. (2005). Determinants of indicated versus actual level of care in psychiatric emergency services. Psychiatric Services, 56(4), 452457.

Murakami, K. (2005, December 15). Housing program for chronic alcoholics allows drinking in rooms. Seattle Post-Intelligencer.

National Alliance to End Homelessness. (2012). Community plans. Retrieved from http://www.endhomelessness.org/section/solutions/community_plans

National Association of Social Workers. (2008). Code of ethics. Retrieved from http://www.socialworkers.org/pubs/code/code.asp

National Association of Social Workers. (2006). Social work speaks: NASW policy statements, 2006-2009. (pp. 202-216).Washington, DC: NASW Press.

National Coalition for the Homeless. (2003). Illegal to be homeless: The criminalization of homelessness in the United States. Retrieved from http://www.nationalhomeless.org /civilrights/crim2003/report1.html

National Coalition for the Homeless. (2010, June). HUD McKinney-Vento programs. Retrieved from http://www.nationalhomeless.org/factsheets/PPR/2010/6\%20\%20HMV\%206-10-10.pdf

National Coalition for the Homeless. (2006, June). Mental illness and homelessness. Retrieved from http://www.nationalhomeless.org/publications/facts/Mental_Illness.pdf 
Running head: RISK FACTORS FOR HOMELESSNESS AMONG MENTAL HEALTH PATIENTS

National Coalition for the Homeless. (2009a, July). Mental illness and homelessness. Retrieved from http://www.nationalhomeless.org/factsheets/Mental_Illness.pdf

National Coalition for the Homeless. (2009b, July). Why are people homeless? Retrieved from http://www.nationalhomeless.org/factsheets/Why.pdf

Nelson, G., Aubry, T. \& Lafrance, A. (2007). A review of the literature on the effectiveness of housing and support, assertive community treatment, and intensive case management interventions for persons with mental illness who have been homeless. American Journal of Orthopsychiatry, 77(3), 350-363.

Nosé, M., Barbui, C. \& Tansella, M. (2003). How often do patients with psychosis fail to adhere to treatment programmes? A systematic review. Psychological Medicine, 33, 1149-1160. doi: 10.1017/S0033291703008328

O’Brien, A., Fahmy, R., \& Singh, S. (2009). Disengagement from mental health services. Social Psychiatry and Psychiatric Epidemiology, 44(7), 558-568. doi: $10.1007 / \mathrm{s} 00127-008-0476-0$

Olfson, M., Mechanic, D., Hansell, S., Boyer, C., \& Walkup, J. (1999). Prediction of homelessness within three months of discharge among inpatients with schizophrenia. Psychiatric Services, 50(5), 667-673.

Olfson, M., Mojtabai, R., Sampson, N., Hwang, I., Druss, B., Wang, P.,...Wells, K. (2009). Dropout from outpatient mental health care in the United States. Psychiatric Services,60(7), 898-907. 
Running head: RISK FACTORS FOR HOMELESSNESS AMONG MENTAL HEALTH PATIENTS

Omnibus Budget Reconciliation Act of 1981, 42 U.S.C. $§ 9902$, et seq. (West, 1981).

O’Toole, T., Pollini, R., Gray, P., Jones, T., Bigelow, G., \& Ford, D. (2007). Factors identifying high-frequency and low-frequency health service utilization among substance-using adults. Journal of Substance Abuse Treatment, 33, 51-59.

Padgett, D., Gulcur, L., \& Tsemberis, S. (2006). Housing first services for people who are homeless with co-occurring serious mental illness and substance abuse. Research on Social Work Practice, 16(1), 74-83.

Pager, D. (2003). The mark of a criminal record. American Journal of Sociology, 108(5), 937-975.

Pager, D., Western, B., \& Bonikowski, B. (2009). Discrimination in a low-wage labor market: A field experiment. American Sociological Review, 74, 777-799. doi: $10.1177 / 000312240907400505$

Pearson, C., Montgomery, A., \& Locke, G. (2009). Housing stability among homeless individuals with serious mental illness participating in housing first programs. Journal of Community Psychology, 37(3), 404-417. doi: 10.1002/jcop.20303

Perlman, J. \& Parvensky, J. (2006). Denver Housing First Collaborative: Cost benefit analysis and program outcomes report. Denver, Colorado: Colorado Coalition for the Homeless. 
Running head: RISK FACTORS FOR HOMELESSNESS AMONG MENTAL HEALTH PATIENTS

Peterson, P., Dimeff, L., Tapert, S., Stern, M., \& Gorman, M. (1998). Harm reduction and HIV/AIDS prevention. In A. Marlatt (Ed.), Harm reduction, (pp. 218-297). New York: Guilford.

Podymow, T., Turnball, J., \& Coyle, D. (2006). Shelter-based managed alcohol administration to chronically homeless people addicted to alcohol. Canadian Medical Association Journal, 174(1), 45-49.

Power, D., French, R, Connelly, J., George, S., Hawes, D., Hinton, T., et al. (1999). Health, health promotion, and homelessness. British Medical Journal, 318, 590592.

Prince, J., Akincigil, A., \& Bromet, E. (2007). Incarceration rates of persons with firstadmission psychosis. Psychiatric Services,58(9), 1173-1180.

Prochaska, J., DiClemente, C., \& Norcross, J. (1992). In search of how people change: Applications to the addictive behaviors. American Psychologist, 47, 1102-1114.

Public Health-Seattle and King County. (2009). Deaths among people presumed homeless in King County: 2007 annual report. Seattle, WA: Author.

Reiman, J., \& Leighton, P. (2010). The rich get richer and the poor get prison: Ideology, class, and criminal justice ( $9^{\text {th }}$ ed.). Upper Saddle River, NJ: Prentice Hall.

Rice, D., \& Sard, B. (2007). Cuts in federal housing assistance are undermining community plans to end homelessness. Washington, D.C.: Center on Budget and Policy Priorities. 
Running head: RISK FACTORS FOR HOMELESSNESS AMONG MENTAL HEALTH PATIENTS

Rossi, A., Amaddeo, F., Bisoffi, G., Ruggeri, M., Thornicroft, G., \& Tansella, M. (2002). Dropping out of care: Inappropriate terminations of contact with communitybased psychiatric services. British Journal of Psychiatry, 181, 331-338. doi: 10.1192/bjp.181.4.331

Rossi, P. (1989). Down and out in America: The origins of homelessness. Chicago: University of Chicago Press.

Ruggeri, M., Salvi, G., Bonetto, C., Lasalvia, A., Allevi, L., Parabiaghi, A., Bertani, M., \& Tansella, M. (2007). Outcome of patients dropping out from community-based mental health care: A 6-year multiwave follow-up study. Acta Psychiatrica Scandinavica, 116, (s437), 42-52. doi: 10.1111/j.1600-0447.2007.01092.x

Saleebey, D. (2006). Introduction . In D. Saleebey (Ed.), The strengths perspective in social work practice, $4^{\text {th }}$ ed., (pp. 1-24). Boston: Allyn and Bacon.

Schwartz, R. (2007). Concurrent validity of the Global Assessment of Functioning scale for clients with schizophrenia. Psychological Reports, 100, 571-574. doi: 10.2466/PR0.100.2.571-574

Seagar, S. (1998). Street crazy: The tragedy of the homeless mentally ill. Redondo Beach, CA: Westcom Press.

Seattle-King County Coalition for the Homeless. (2008). 2008 annual one night count of people who are homeless in King County, WA. Seattle, WA: Author. 
Sharfstein, S. (2000). Whatever happened to community mental health? Psychiatric Services, 51(5), 616-620.

Shelton, K., Taylor, P., Bonner, A., \& van den Bree, M. (2009). Risk factors for homelessness: Evidence from a population-based study. Psychiatric Services, 60(4), 465-472. doi: 10.1176/appi.ps.60.4.465

Shern, D., Tsemberis, S., Anthony, W., Lovell, A., Richmond, L., Felton, H. et al. (2000). Serving street-dwelling individuals with psychiatric disabilities: Outcomes of a psychiatric rehabilitation clinical trial. American Journal of Public Health, 90(12), 1873-1878.

Shirk, C. (2008). Medicaid and mental health services. Background Paper No. 66. Washington, D.C.: National Health Policy Forum.

Shumway, M., Boccellari, A., O’Brien, K., \& Okin, R. (2008). Cost-effectiveness of clinical case management for ED frequent users: Results of a randomized trial. American Journal of Emergency Medicine, 26(2), 155-164. doi:10.1016/j.ajem.2007.04.021

Snow, D., Baker, S., \& Anderson, L. (1989). Criminality and homeless men: An empirical assessment. Social Problems, 36(5), 532-549.

Snowden, L. (1999). African American service use for mental health problems. Journal of Community Psychology, 27(3), 303-313. 
Startup, M., Jackson, M., \& Bendix, S. (2002). The concurrent validity of the Global Assessment of Functioning (GAF). British Journal of Clinical Psychology, 41, 417-422.

Stewart B. McKinney Homeless Assistance Act of 1987, 42 U.S.C. $§ 11302$ et seq. (West 1987).

Substance Abuse and Mental Health Services Administration. (2003a). 2003 CMHS exemplary programs [Brochure]. Rockville, MD: Author.

Substance Abuse and Mental Health Services Administration. (2012). About PATH. Retrieved from http://pathprogram.samhsa.gov/Super/Path/About.aspx

Substance Abuse and Mental Health Services Administration. (2003b). Blueprint for change: Ending chronic homelessness for persons with serious mental illness and/or co-occurring substance use disorders. DHHS Pub. No. SMA-04-3870, Rockville, MD: Center for Substance Abuse and Mental Health Services Administration.

Substance Abuse and Mental Health Services Administration. (2009). Results from the 2008 National Survey on Drug Use and Health: National Findings (Office of Applied Studies, NSDUH Series H-36, HHS Publication No. SMA 09-4434). Rockville, MD: Center for Substance Abuse and Mental Health Services Administration. 
Running head: RISK FACTORS FOR HOMELESSNESS AMONG MENTAL HEALTH PATIENTS

Swartz, M., Wilder, C., Swanson, J., Van Dorn, R., Robbins, P., Steadman, H., ... Monahan, J. (2010). Assessing outcomes for consumers in New York's assisted outpatient treatment program. Psychiatric Services, 61(10) 976-981.

Swartz, R. (2007). Concurrent validity of the Global Assessment of Functioning scale for clients with schizophrenia. Psychological Reports, 100, 571-574. doi: 10.2466/PR0.100.2.571-574

Thompson, E., Neighbors, H., Munday, C., \& Jackson, J. (1996). Recruitment and retention of African American patients for clinical research: An exploration of response rates in an urban psychiatric hospital. Journal of Consulting and Clinical Psychology, 64(5), 861-867.

Tsemberis, S., Gulcur, L., \& Nakae, M. (2004). Housing first consumer choice, and harm reduction for homeless individuals with a dual diagnosis. American Journal of Public Health, 94(4), 651-657.

Tsemberis, S., \& O’Callagham, S. (2004). Harm reduction. In D. Levinson (Ed.), Encyclopedia of homelessness (Vol. 1, pp. 189-193). Thousand Oaks, CA: Sage.

UN General Assembly. (1948). Universal declaration of human rights (217A [III] U.N.

Doc A/810 at 71). New York: United Nations Retrieved from: http://www.unhcr.org/refworld/docid/3ae6b3712c.html

U.S. Census Bureau (2001). Emergency and transitional shelter populations: 2000. Washington, DC: U.S. Government Printing Office. 
U.S. Census Bureau. (2010). State and city Quickfacts: San Diego County, C.A.

Retrieved from http://quickfacts.census.gov/qfd/states/06/06073.html

U.S. Census Bureau. (2010). State and city Quickfacts: Seattle, W.A. Retrieved from http://quickfacts.census.gov/qfd/states/53/5363000.html

U.S. Census Bureau. (2010). State and county Quickfacts: USA. Retrieved from http://quickfacts.census.gov/qfd/states/00000.html

U.S. Conference of Mayors. (2007). Hunger and homelessness survey: 2007. Washington, D.C.: Author.

U.S. Department of Housing and Urban Development. (2011). Affordable housing. Retrieved from http://www.hud.gov/offices/cpd/affordablehousing

U.S. Department of Housing and Urban Development. (2012). Homeless assistance programs. Retrieved from http://portal.hud.gov/hudportal/HUD?src=/program_offices/ comm_planning/homeless/programs

U.S. Department of Housing and Urban Development. (2008). Overview of the supportive housing program: Program components. Retrieved from http://www.hud.gov/offices /cpd/homeless/library/shp/understandingshp/ components.cfm

U.S. Department of Housing and Urban Development. (2010). The 2010 annual homeless assessment report to Congress. Washington, D.C.: Author. 
Running head: RISK FACTORS FOR HOMELESSNESS AMONG MENTAL HEALTH PATIENTS

U.S. Interagency Council on Homelessness. (2008). State and local initiatives. Retrieved from http://www.ich.gov/slocal/index.html

U.S. Interagency Council on Homelessness. (2012). United States Interagency Council on Homelessness historical overview. Retrieved from http://www.usich.gov/resources/ uploads/asset_library/RPT_USICH_History_final_2012.pdf

U.S. Social Security Administration. (2012). Homeless outreach projects and demonstration. Retrieved from http://www.ssa.gov/disabilityresearch/hope.htm

Wang, J. (2007). Mental health treatment dropout and its correlates in a general population sample. Medical Care, 45(3), 224-229.

Western, B. \& Pettit, B. (2010). Incarceration and social inequality. Daedalus, 139(3), 819.

Western Regional Advocacy Project. (2006). Without housing: Decades of federal housing cutbacks, massive homelessness, and policy failures. San Francisco, CA: Author.

Wierzbicki, M., \& Pekarik, G. (1993). A meta-analysis of psychotherapy dropout. Professional Psychology: Research and Practice, 24(2), 190-195.

Wilper, A., Woolhandler, S., Boyd, W., Lasser, K., McCormick, D., Bor, D., ... Himmelstein, D. (2009). The health and health care of US prisoners: Results of a 
Running head: RISK FACTORS FOR HOMELESSNESS AMONG MENTAL HEALTH PATIENTS

nationwide survey. American Journal of Public Health, 99(4), 666-672. doi: 10.2105/AJPH.2008.144279

World Health Organization. (1986). Ottawa Charter for Health Promotion. Health Promotion 1(4), iii-v.

World Health Organization. (2002). World health report 2002: Reducing risks, promoting healthy life. Geneva, Switzerland: Author. 